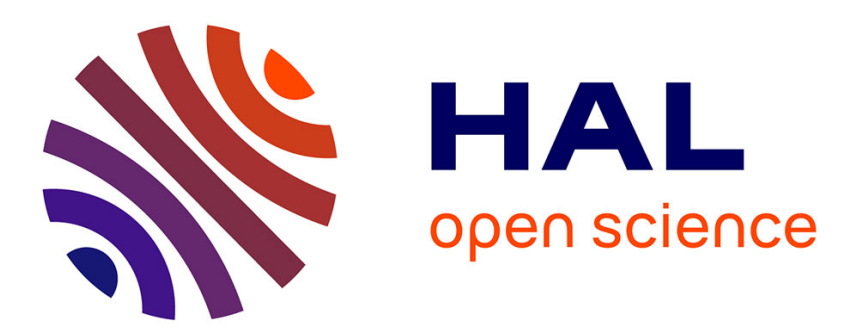

\title{
Flip-flop kinetics of ropivacaine during continuous epidural infusion influences its accumulation rate
}

Maria Cusato, Massimo Allegri, Tekla Niebel, Pablo Ingelmo, Monica Broglia, Antonio Braschi, Mario Regazzi

\section{- To cite this version:}

Maria Cusato, Massimo Allegri, Tekla Niebel, Pablo Ingelmo, Monica Broglia, et al.. Flip-flop kinetics of ropivacaine during continuous epidural infusion influences its accumulation rate. European Journal of Clinical Pharmacology, 2010, 67 (4), pp.399-406. 10.1007/s00228-010-0927-x . hal-00642397

\section{HAL Id: hal-00642397 https://hal.science/hal-00642397}

Submitted on 18 Nov 2011

HAL is a multi-disciplinary open access archive for the deposit and dissemination of scientific research documents, whether they are published or not. The documents may come from teaching and research institutions in France or abroad, or from public or private research centers.
L'archive ouverte pluridisciplinaire HAL, est destinée au dépôt et à la diffusion de documents scientifiques de niveau recherche, publiés ou non, émanant des établissements d'enseignement et de recherche français ou étrangers, des laboratoires publics ou privés. 


\section{FLIP-FLOP KINETICS OF ROPIVACAINE DURING CONTINUOUS EPIDURAL} INFUSION INFLUENCES ITS ACCUMULATION RATE

Cusato $M^{1}$, Allegri $M^{2}$, Niebel $T^{2,3}$, Ingelmo $P^{4}$, Broglia $M^{1}$, Braschi $A^{2,5}$, Regazzi $M .^{1}$

${ }^{1}$ Laboratory of Clinical Pharmacokinetics, Foundation IRCCS Policlinico San Matteo, Pavia, Italy;

${ }^{2}$ Department of Anesthesia and Intensive Care I and Pain Therapy, Foundation IRCCS Policlinico San Matteo, Pavia, Italy;

${ }^{3}$ Department of Surgical Science- Pavia's University, Pavia, Italy;

${ }^{4}$ First Service of Anesthesia and Intensive Care San Gerardo Hospital Monza (MI) Department of Experimental Medicine Milan Bicocca's University, Milan, Italy;

${ }^{5}$ Department of Resuscitation and Organ Transplantation Surgery Sciences, Section of Anesthesiology and Resuscitation, University of Pavia

Correspondence to:

Dr. Mario Regazzi

Head of Laboratory of Clinical Pharmacokinetics

Foundation IRCCS Policlinico San Matteo

P.le Golgi, 2

I - 27100 Pavia

Italy

Tel. +390382 503471

Fax +390382 422701

e-mail address: regazzim@smatteo.pv.it

\section{Acknowledgements:}

This research is supported by a grant of Scientific Direction of Fondazione IRCCS Policlinico San Matteo, Pavia, Italy. 


\section{Abstract}

Background

Ropivacaine has an optimal toxicity profile for epidural anesthesia in adults, but there are currently no studies concerning its pharmacokinetics during continuous infusion. The primary objective of this study was to evaluate the pharmacokinetics and safety of ropivacaine in adults during a 48-hours continuous epidural infusion.

\section{Materials and methods}

We enrolled 43 adults (ASA I-II) scheduled for major abdominal or urologic surgery with postoperative continuous epidural analgesia with ropivacaine $0.2 \%(5 \mathrm{~mL} / \mathrm{h})$ and sufentanil $0.75 \mu \mathrm{g} / \mathrm{mL}$ for 48 hours.

Deleted: $5 \mathrm{~mL} / \mathrm{h}$

Ropivacaine blood samples were collected, during continuous epidural infusion, before the bolus and 3, 6, 12, 24, 48, 54, 60 hours after the bolus; plasma concentrations were measured on HPLC-UV. The concentration-time relationship of ropivacaine levels was analyzed using a population pharmacokinetic method based on a mixed-effect-model approach (P-PHARM software).

\section{Results}

Mean plasma concentration of ropivacaine at the end of epidural infusion $\left(\mathrm{C}_{48 \mathrm{~h}}\right)$ was $1.69 \mu \mathrm{g} / \mathrm{mL}(0.21-3.8 \mu \mathrm{g} / \mathrm{mL})$. Mean (range) $C_{\text {max }}$, was $1.82 \mu \mathrm{g} / \mathrm{L}(0.61-4.0 \mu \mathrm{g} / \mathrm{mL})$; the area under the plasma concentration curve, $A \cup C_{(0-60)}$, was $67.48 \pm 30.60 \mu \mathrm{g} . \mathrm{h} / \mathrm{mL}$.

Total plasma ropivacaine concentrations fell mainly within (84\%) or below (12\%) the range reported to be safe in adults $(1.0-3.0 \mu \mathrm{g} / \mathrm{mL})$. Only 2 patients $(5 \%)$ reached ropivacaine plasma levels higher than $3 \mu \mathrm{g} / \mathrm{mL}$, namely 3.8 and $4.0 \mu \mathrm{g} / \mathrm{mL}$ at 48 and 54 hours, respectively. Total ropivacaine concentrations up to $4.0 \mu \mathrm{g} / \mathrm{mL}$ were tolerated during long-term epidural ropivacaine infusion.

Mean clearance for total ropivacaine was $5.33 \mathrm{~L} / \mathrm{h}$. Age was the only covariable to Deleted: (CV 22\%) significantly reduce clearance variability: $\mathrm{CL}_{-}(\mathrm{L} / \mathrm{h})=15.04-0.148{ }^{*}$ age (years). The volume of distribution $(\mathrm{Vd})$ was $92.15 \mathrm{~L}_{\mathrm{r}}$ The infusion dosing period half-life $\left(\mathrm{t}_{1 / 2, \mathrm{DP}}=\right.$ Deleted: (CV 16.4\%) $0.693{ }^{*} \mathrm{Vd} / \mathrm{CL}$ ) was 10.8 hours.

\section{Conclusions}

Exposure to ropivacaine during epidural infusion is highly variable. The apparent infusion dosing half-life $t_{1 / 2, \mathrm{DP}}$ is the most appropriate parameter to predict drug 
accumulation upon epidural infusion since it appears to better reflect the interplay interference between volume distribution and absorption rate during the accumulation phase. Prediction of ropivacaine accumulation can be improved by considering patient age. 


\section{Introduction}

Ropivacaine (RPV) is a long-acting amide-type local anesthetic with a similar structure to bupivacaine [1]. Many literature studies have demonstrated the clinical efficacy of ropivacaine $0.2 \%$ epidural infusion, with only some individual case reports of major side-effects. [2,3,4,5] Although ropivacaine is a safer alternative to bupivacaine, excessive plasma concentrations of ropivacaine can cause severe central nervous system and cardiac toxicity. After epidural administration, both the systemic absorption and the systemic disposition of ropivacaine play an important role in determining the clinical profile and the risk of systemic toxicity. $[6,7,8,9]$

Ropivacaine calculated terminal half-life is significantly longer after epidural than after intravenous administration. Ropivacaine absorption after epidural administration cannot be derived directly from plasma concentration-time curves because of flip-flop kinetics. $[9,10]$ The flip-flop model implies slow absorption of ropivacaine from the epidural space into the systemic circulation rate-limits drug elimination. Therefore, when the process of absorption is a limiting factor, the terminal half-life reflects the rate and the extent of absorption and not the elimination process. $[10,11]$ In a system consisting of a series of processes, the decrease in concentrations after administration is discontinued and the time to reach the steady-state depends on the slowest process in the chain. This has implication for designing epidural continuous infusion schedules of ropivacaine, considering the clinical significance of accumulation reaching either toxic or ineffective concentrations.

The primary goal of this study was to evaluate the pharmacokinetics of ropivacaine accumulation in adults receiving continuous epidural analgesia during the first $48 \mathrm{~h}$ after major surgery.
Formatted: Not Superscript/ Subscript

Formatted: Not Superscript/

Subscript

Formatted: Not Superscript/ Subscript

Formatted: Not Superscript/

Subscript

Formatted: Not Superscript/ Subscript 


\section{Material and methods}

After approval from the Ethics Committee of San Matteo Hospital (EudraCT number 2010-019393-32) and written informed consent 49 adult patients, ASA class I-II, scheduled for major abdominal or urological surgery and planned to receive a postoperative epidural infusion after surgery for pain control were enrolled. Exclusion criteria were emergency surgery, coagulopathy, renal, hepatic, neurological or psychiatric diseases, a history of peripheral neuropathies and chronic opioid therapy.

Before anesthesia induction epidural catheter was positioned in sitting position, using the loss resistance technique. In patients scheduled for upper abdominal surgery the epidural catheter was placed between T7-T8 or T9-T10. In patients scheduled for lower abdominal or urologic surgery between T10-T11. General anesthesia was induced with Propofol $2 \mathrm{mg} / \mathrm{kg}$, Fentanyl $2 \mu \mathrm{g} / \mathrm{kg}$, Cisatracurium $0.15 \mathrm{mg} / \mathrm{kg}$, and was maintained with Fentanyl and Sevoflurane $2 \%$. Forty five minutes before the end of surgery patients received an epidural loading dose (RPV $0.2 \% 5 \mathrm{ml}$ + Sufentanil $10 \mu \mathrm{g}$ ), followed by a second bolus (RPV 02\% $5 \mathrm{ml}$ ) 15 minutes later. At the end of surgery an epidural infusion of Ropivacaine $0.2 \%$ plus Sufentanil $0.8 \mu \mathrm{g} / \mathrm{ml}$ was started. Ropivacaine/Sulfentanyl epidural infusion was constantly condelivered at a rate of $5 \mathrm{ml} / \mathrm{h}$ using an electronic infusion pump during the first 48 hs after surgery.

Patients were evaluated every 6 hours during the first day after surgery and every 12 hours in the second postoperative day. We recorded vital signs (arterial pressure and heart rate), pain according to the Numeric Rate Scale (at rest - NRS - and after movement -mNRS-), analgesic rescue dose (administered if NRS>4), Holmen scale (to assess if there was sensory block), sedation scale and clinical side-effects (nausea, vomiting, itching, hypotension, systemic neurological side effects)

\section{Reagents}

RPV was a gift of the Department of Anesthesia and Intensive Care. Phenacetin was purchased from Sigma (St. Louis, MO, USA). All other chemicals and reagents used were of the highest commercially available quality. 
The HPLC system consisted of Varian Prostar Mod.430 a pump equipped with variable-wavelength UV detector (Varian Prostar Mod.330). Separation was achieved using a reverse-phase $\mathrm{C}-18$ column $(250 \times 4.6 \mathrm{~mm}$ I.D., particle size $5 \mu \mathrm{m}$, Hypersil BDS-CPS Analitica, Italy). The mobile phase was acetonitrile-methanol-50mM potassium dihydrogen phosphate $(\mathrm{pH}=6)(180: 160: 660, \mathrm{v} / \mathrm{v} / \mathrm{v})$ delivered at a flow rate of $1.3 \mathrm{~mL} / \mathrm{min}$. Chromatographic separation was performed at laboratory room I temperature and monitored at $210 \mathrm{~nm}$.

The HPLC method has been validated over the range $0.1-4 \mu \mathrm{g} / \mathrm{mL}$. The assay was linear over the entire concentration range $\left(r^{2}=0.99\right)$. Intra- and inter-day precision and accuracy was less than $6 \%$.

The limit of detection (LOD) was $0.050 \mu \mathrm{g} / \mathrm{mL}$, the limit of quantification (LOQ) was 0.1 $\mu \mathrm{g} / \mathrm{mL}$.

\section{Preparation of Standard solution and standard curves}

A standard stock solution $(1 \mathrm{mg} / \mathrm{mL})$ of drug was prepared in methanol-water $(50 / 50)_{2}$ stored at $-20^{\circ} \mathrm{C}$ and were stable for at least 6 months. Plasma standards and controls were prepared at concentrations of $0.1,0.2,0.4,1.0,2.0,4.0 \mu \mathrm{g} / \mathrm{mL}$ and 0.12 (Low), 0.8 (Medium) and 1.6 (High) $\mu \mathrm{g} / \mathrm{mL}$, respectively, by diluting appropriate aliquots of the stock solution with drug-free serum. The calibration curve was obtained by linear regression of the peak-height ratios of ropivacaine to the internal standard and plotting these against the nominal concentration of the drug.

\section{Blood sampling}

Blood samples were obtained immediately before bolus drug administration and 3, 6 , 12, 24, 48, 54 and $60 \mathrm{~h}$ after starting the infusion. Plasma was separated by centrifugation, transferred to clean prelabeled tubes and frozen at $-20^{\circ} \mathrm{C}$ until analysis.

\section{Sample preparation}

$250 \mu \mathrm{L}$ of distilled deionized water,500 $\mu \mathrm{L}$ of dichloromethane and $10 \mu \mathrm{L}$ phenacetin (10 $\mu \mathrm{g} / \mathrm{mL}$, I.S.) were added to $250 \mu \mathrm{L}$ of plasma. After vortex mixing for 3 minutes, the tubes were centrifuged at $1200 \mathrm{~g}$ for $10 \mathrm{~min}$. The organic phase was transferred into a clean conical tube and evaporated to dryness under a gentle nitrogen stream. The residue was dissolved in $200 \mu \mathrm{L}$ mobile phase and $50 \mu \mathrm{L}$ was injected into HPLC.

\begin{tabular}{|l|}
\hline Deleted: equipment \\
\hline Deleted: a pump ( \\
\hline Deleted: ) \\
\hline Deleted: and a \\
\hline Deleted: C $_{18}$ \\
\hline Deleted: \\
\hline Deleted: y \\
Formatted: Font: (Default) Arial, Not \\
Deleted: KH2PO4 \\
Formatted: Not Superscript/ \\
Subscript \\
\hline Formatted: Not Superscript/ \\
Subscript \\
\hline Deleted: and \\
Deleted: the \\
Deleted: was \\
\hline
\end{tabular}

Deleted: and

Deleted: for at least 6 months 


\section{Pharmacokinetic analysis}

The concentration-time relationship of ropivacaine levels (corresponding to 6 data points) during an epidural infusion preceded by 2 sequential boluses was analyzed using a population pharmacokinetic method based on a mixed-effect-model approach. This method separates explicitly the variability of drug concentrations in the population into two parts: interindividual variability characterized by the distribution of pharmacokinetic parameters in the population and residual variability (e.g., measurement errors). A parametric approach $[12,13]$ was used (using the P-PHARM software, which is now incorporated into the Innaphase Kinetica suite) to estimate the mean and interindividual variance of each pharmacokinetic parameter in the population, to calculate the Bayesian maximum a posteriori estimates of individual pharmacokinetic parameters, and to test the relationships between these individual estimates and several covariates (gender, age, body weight, height, renal and hepatic function indices). During covariate modeling, P-PHARM can automatically search for a linear relationship between covariates and the population parameter estimates.

Pharmacokinetic data were fitted with different compartmental models. The most appropriate model was chosen based on the Akaike information criterion [12] and the examination of residual plots. A one-compartment model with sequential bolus and infusion inputs was fitted to the total plasma ropivacaine concentration-time data.

Formatted: Not Superscript/ The plasma concentration versus time curve of ropivacaine during continuous epidural infusion ( $R_{0}$ : rate of epidural infusion) was described by the equation:

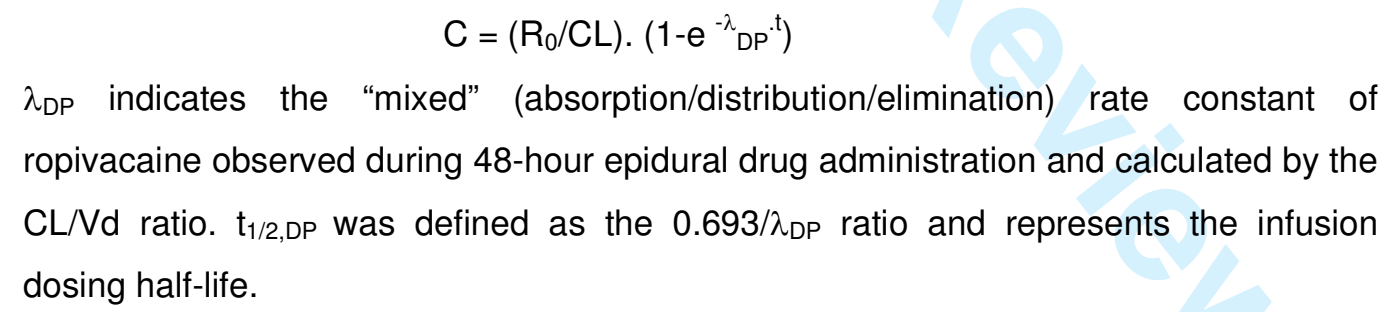$$
C=\left(R_{0} / C L\right) \cdot\left(1-e^{-\lambda} D P^{\cdot t}\right)
$$$$
\lambda_{\mathrm{DP}} \text { indicates the "mixed" (absorption/distribution/elimination) rate constant of }
$$
ropivacaine observed during 48-hour epidural drug administration and calculated by the $\mathrm{CL} / \mathrm{Vd}$ ratio. $\mathrm{t}_{1 / 2, \mathrm{DP}}$ was defined as the $0.693 / \lambda_{\mathrm{DP}}$ ratio and represents the infusion dosing half-life.

Ropivacaine pharmacokinetic starting estimates for the population analysis were obtained from previous studies. A heteroscedastic error variance $(1 / Y)$ model was used to describe residual error, and a log-normal distribution was used to describe 
interpatient variability in apparent clearance $(C L)$ and apparent volume of distribution $(\mathrm{Vd})$.

When bioavailability $(F)$ is not known, estimates of $C L$ should be related to $F$, i.e., $C L / F$. Bioavailability was fixed to 1 , assuming total (100\%) absorption after epidural administration. Model evaluation was conducted as recommended in the P-PHARM manual and also by examination of a plot of measured/predicted concentration data versus time.

After the end of infusion, the terminal rate constant $(\lambda$,terminal $)$ was determined for total ropivacaine by linear regression of the last 3 data points on the plasma concentrationtime curve (from the $48^{\text {th }}$ hour to the $60^{\text {th }}$ hour):

$$
\mathrm{C}^{\prime}=\mathrm{C}_{48 \mathrm{~h}} \cdot \mathrm{e}^{-\lambda} \text { terminal } \cdot \mathrm{t}^{\prime}
$$

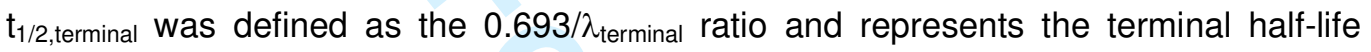
after the infusion is stopped. $t$ ' is the time since the end of the infusion.

The area under the plasma concentration time curve was calculated by numeric integration using the linear trapezoidal rule. $C_{\max }$ was the highest concentration achieved; the time to $C_{\max }$ and the plasma concentrations at $3,6,12,24,48,54$ and 60 $\mathrm{h}$ after starting ropivacaine administration $\left(\mathrm{C}_{3 \mathrm{~h}}, \mathrm{C}_{6 \mathrm{~h}}, \mathrm{C}_{12 \mathrm{~h}}, \mathrm{C}_{24 \mathrm{~h}}, \mathrm{C}_{48 \mathrm{~h}}, \mathrm{C}_{54 h}, \mathrm{C}_{60 \mathrm{~h}}\right.$, respectively) were derived directly from ropivacaine levels.

\section{Statistical analysis}

Patient characteristics are summarized as median values (range). Total plasma ropivacaine concentrations and derived pharmacokinetic data are summarized as geometric mean (geometric coefficient of variation, CV\%) and/or mean $( \pm S D)$ values. Multiple-linear regression analysis with stepwise inclusion between maximum a posteriori estimates of all pharmacokinetic parameters and all covariates was performed with the analysis of variance to determine the relevant relationships (with the P-PHARM software). [12] A value of $P<0.05$ was considered significant. 


\section{Results}

Forty-nine adults consecutive were enrolled and six were excluded after discontinuation of epidural continuous infusion because of clinical or hemodynamic problems not related to ropivacaine epidural infusion; data collection was incomplete in one other Deleted: patient, whose data were nevertheless included in our PK analysis. Forty-three patients completed the analysis.

Thirty-five patients underwent major abdominal surgery and eight underwent urological surgery (29 males and 14 females). Patient age ranged from 41 to 83 years (median=63 years) and body weight ranged from 50 to $100 \mathrm{~kg}$ (median=75.5 kg).

Analgesia was satisfactory in all cases and there were no cardiocirculatory side-effects, such as major hypotension or arrhythmia, which could require discontinuation of the epidural infusion. There were no minor (facial dysthesia, tinnitus, changes in sensitivity and strength) or major (convulsions, hallucinations) neurological complications during continuous epidural infusion of ropivacaine.

A total of 330 plasma concentrations from 43 patients were used to compute pharmacokinetic parameters including a baseline sample, four samples collected during ropivacaine infusion and three samples collected during the first $12 \mathrm{~h}$ after ropivacaine infusion discontinuation.

Pharmacokinetic data (geometric mean and geometric coefficient of variation, CV\%) are summarized in Table I.

During the epidural infusion (ropivacaine $10 \mathrm{mg} / \mathrm{h}$ ) preceded by 2 sequential boluses of $10 \mathrm{mg}$ each, plasma concentrations of ropivacaine leveled off, as expected. Exposure to ropivacaine during epidural infusion was highly variable.

The plasma concentration of ropivacaine at the end of epidural infusion $\left(\mathrm{C}_{48 \mathrm{~h}}\right)$ was 1.60 $\pm 0.89 \mu \mathrm{g} / \mathrm{mL}$. After 12 hours and 24 hours, respectively, $\sim 50 \%$ and $\sim 75 \%$ of the 48 hour level of ropivacaine were reached. $C_{\max }$, was $1.82 \pm 0.89 \mu \mathrm{g} / \mathrm{L}$ and was observed at a mean time $\left(t_{\max }\right)$ of 48 hours.

Total plasma ropivacaine concentrations were mainly within $(84 \%)$ or below $(12 \%)$ the | range reported to be safe in adults $(1.0-3.00 \mu \mathrm{g} / \mathrm{mL})$. $[5,6,9,14,15,16]$ Only 2 patients (5\%) reached ropivacaine plasma levels higher than $3.0 \mu \mathrm{g} / \mathrm{mL}$, namely 3.8 and 4.0 
$\mu \mathrm{g} / \mathrm{mL}$ at 48 and 54 hours, respectively. Total ropivacaine concentrations up to 4.0 $\mu \mathrm{g} / \mathrm{mL}$ were tolerated during long-term epidural ropivacaine infusion.

Figure 1 shows all the measured plasma ropivacaine concentrations and the drug concentration-time curve resulting from the average population parameters estimated with P-Pharm.

Estimated population characteristics of the kinetic parameters together for ropivacaine clearance $(\mathrm{CL})$ and the apparent volume of distribution $(\mathrm{Vd})$ with their coefficient of variation are presented in Table II.

The dosing period absorption/distribution/elimination rate constant of ropivacaine calculated by the average population parameters $\left(\lambda_{D P}=C L / V d\right)$ was $0.064 h^{-1}$ and the corresponding $t_{1 / 2, D P}=\left(0.693^{*} \mathrm{Vd}\right) / C L=10.8$ hours.

Following the end of epidural infusion of ropivacaine, the terminal half-life $\left(\mathrm{t}_{1 / 2, \text { terminal }}\right)$, determined for total ropivacaine by linear regression of the last 3 data points on the plasma concentration-time curve was 7.4 hours.

The pharmacokinetic population parameters were subsequently used to fit the concentration data up to $48 \mathrm{~h}$ using the Bayesian estimation method. This procedure enables the estimation of individual pharmacokinetic parameters for ropivacaine. The individual posterior Bayesian estimates of ropivacaine pharmacokinetic parameters were generated using a maximum a posteriori probability Bayesian fitting procedure. ${ }^{23} 1$ The performance of individualized Bayesian estimation steps is shown in the plots of the observed versus estimated plasma concentrations in Figure 2, and by the frequency distribution histogram of the normalized residuals which revealed a distribution very close to the expected one (normal with zero mean and unitary variance).

Through covariate analysis, we found that age was the only independent predictor identified.

In fact, the stepwise inclusion performed on P-PHARM revealed an age effect on CL, which explains $39.8 \%$ of the interindividual variability of the population pharmacokinetic parameters. Ropivacaine clearance correlated inversely with age. The linear correlation between age and ropivacaine clearance was best described by the equation (least square regression; $r=0.63, p<0.001$ ):
Deleted: $u$

Deleted: The population geometric mean estimates for ropivacaine clearance $(\mathrm{CL})$ and the $\mathrm{Vd}$ were 5.33

$\mathrm{L} / \mathrm{h}$ and $92.15 \mathrm{~L}$, respectively. The

estimated interpatient variability (expressed as a coefficient of variation) in ropivacaine clearance and volume of distribution was $21.7 \%$ and $16.4 \%$, respectively. $\mid$ 


\section{Discussion}

Pharmacokinetic of epidural ropivacaine was well described after single dose, but it was important to detect what it can happen during continuous infusion. Whereby we investigated which kind of kinetic we have during epidural continuous infusion and if there are predictors that can determine a change in the pharmacokinetic profile.

In fact, plasma concentration profiles and the potential risk of systemic toxicity after epidural administration of ropivacaine depends on the administered dose and the interaction between the rate processes involved in drug absorption and systemic disposition. [2,16,17,18,19] Unfortunately, absorption and disposition kinetics cannot be derived directly from the plasma concentration-time profile, since local anesthetics exhibit flip-flop kinetics after epidural administration. In a system consisting of a series of processes or compartments, not only the decrease in the concentrations after stopping administration but also the time to reach steady-state depend on the slowest process in the chain.

Half-life is the most clinically relevant pharmacokinetic parameter to predict drug accumulation time in a patient upon constant rate administration. Problems arise when we have to pick the half-life upon which to calculate drug accumulation. Also, when estimating the time for the epidural administration to achieve steady-state, we have to decide if we should work with the actual elimination half-life of ropivacaine obtained from the PK of the intravenous formulation $\left(\mathrm{t}_{1 / 2, \mathrm{IV}}\right)$,consider the terminal half-life calculated after the end of the infusion ( $t_{1 / 2, \text { terminal }}$ ), or take into account the "mixed" absorption/distribution/elimination half-life estimated during the epidural infusion $\left(\mathrm{t}_{1 / 2, \mathrm{DP}}\right)$.

When the process of absorption is not a limiting factor, half-life is a hybrid parameter controlled by plasma clearance and extent of distribution. When the process of absorption is a limiting factor, the terminal half-life reflects mainly the rate and extent of absorption and not the elimination process (flip-flop pharmacokinetics). [20] Our data indicate that the true half-life of ropivacaine, as reported after IV administration $\left(\mathrm{t}_{1 / 2, \mathrm{IV}}\right.$ $1.8 \pm 0.7$ hours) [21], is irrelevant to the time to reach steady-state.

Formatted: Not Superscript/ Subscript

Formatted: Not Superscript/ Subscript 
In order to predict drug accumulation upon epidural infusion dosing, it is more appropriate to use the apparent infusion dosing half-life $t_{1 / 2, D P}$ since this parameter appears to better reflect the interplay interference between volume distribution and absorption rate during the accumulation phase. Our data indicate that this infusion dosing period half-life ( $\mathrm{t}_{1 / 2 \mathrm{DP}}=10.8$ hours) was higher $(\uparrow 45 \%)$ than the terminal half-life $\left(t_{1 / 2 \text { terminal }}=7.4\right.$ hours $)$; a more pronounced sensitivity of the $t_{1 / 2 D P}$ to the absorption rate process probably explains the difference. This difference seems to confirm the indication by Sahin and Benet [22] to avoid the acritical use of a drug's terminal half-life to predict the drug's accumulation rate.

A one-compartment model with zero-order input and first-order elimination was optimal for describing the data in the accumulation phase during epidural infusion of ropivacaine. The same model was used by Hansen et al. [16] to describe the trend of ropivacaine concentrations during the accumulation phase in pediatric patients (mean age: 3.3 years, range: 0.3-7.3 years) under continuous epidural infusion. In the majority of children ropivacaine concentrations had reached the steady-state within 36 hours and the half life $\left(\mathrm{t}_{1 / 2 \mathrm{DP}}\right)$ of total ropivacaine was 4.9 hours. The apparent total clearance $(0.51 \mathrm{~L} / \mathrm{h} / \mathrm{kg})$ and the apparent volume of distribution $(3.1 \mathrm{~L} / \mathrm{kg})$ were about six and three times the values obtained in our adult patients, respectively. The pharmacokinetic parameters obtained in our study from data following continuous epidural infusion are different from the corresponding values reported after IV administration (Vd: 88.8L vs. 41.7L, CL: 5.7L/h vs. 23.2L/h) in adult patients. On the other hand, the final parameters of ropivacaine obtained by a population pharmacokinetic analysis $\left.\_23\right]$ (NONMEN) after loco-regional administration as an anesthetic in hip or knee replacement surgery were quite similar: the apparent clearance was $3.5 \mathrm{~L} / \mathrm{h}$ and the volume of distribution was 65.3L. When evaluating the individual pharmacokinetic parameters, though, we must keep in mind that modeling is always dangerous if no IV data are available, because we may get a good fit of data to our equations but the parameters are hybridized and therefore incorrect. It has been underlined that when one models with sums of exponentials, one can simply assume consistency (best to assume this for the equation and not the model). Thus, good fits do not validate our model but only indicate consistency. In most cases, like this one, it is not strictly necessary to assume
Formatted: Not Superscript/

Subscript

Formatted: Not Superscript/ Subscript

Formatted: Not Superscript/ Subscript 
validation_[20]. Modeling with sums of exponentials is feasible, as long as the results are reported in terms of macroscopic parameters (coefficients and exponents) and model-independent parameters, such as mean systemic or oral clearance, which is always dose over AUC (Table II).

For a drug such as ropivacaine, the time to reach the steady-state may be influenced by the absorption rate (if administered by extravascular route), by the volume of distribution and by clearance; however, mean steady-state concentration depends only on clearance. Also, it is well recognized that clearance (divided by bioavailability) defines the appropriate rate of administration of a particular drug through the relationship: $R_{0}=C L . C_{s s, a v e} . F$. For ropivacaine $(10 \mathrm{mg} /$ hour), a drug following linear

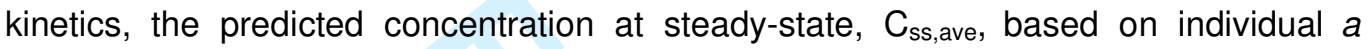
posteriori Bayesian estimates of ropivacaine pharmacokinetic clearance resulted in a mean value of $2.0( \pm 0.62) \mu \mathrm{g} / \mathrm{mL}$. At the end of infusion (48 $\mathrm{h}$ after the start of treatment) the ropivacaine plasma levels achieved corresponded on average to $\sim 90 \%$ of the levels that would be achieved at the steady-state.

Our data showed that prediction of ropivacaine accumulation can be improved by considering patient age. After epidural infusion, a trend towards a lower total plasma clearance with increasing age was observed (Fig.3). Simon et al.[24] studied the influence of age on pharmacokinetics of ropivacaine after single epidural administration and reported similar results: clearance js significantly decreased jn the oldest patients relative to the youngest ones, In our study we confirmed that also during continuous infusion there is an inversely correlation between age and clearance. In fact RPV clearance in a 40-year-old individual is about twice as high as in a 70-year-old subject. As ropivacaine is extensively metabolized in the liver_[8], the age dependence in clearance may presumably reflect decreased enzyme activity.

Studies during prolonged epidural infusion of ropivacaine showed that postoperative increases in plasma alpha ${ }_{1}$-acid glycoprotein concentrations are associated with increases in the plasma protein binding and in the total plasma concentrations of ropivacaine. Ropivacaine total clearance depends on liver enzyme activity and on the
Formatted: Not Superscript/ Subscript

Formatted: Font color: Auto

\begin{tabular}{|l|}
\hline Deleted: \\
\hline Formatted: Not Superscript/ \\
Subscript \\
\hline Deleted: \\
\hline Deleted: results, \\
Deleted: that \\
\hline Deleted: a \\
\hline Deleted: clearance \\
\hline Deleted: \\
Formatted: Not Superscript/ \\
\hline
\end{tabular}


free drug fraction in plasma $\left(C L \sim \mathrm{CL}_{\mathrm{i}}{ }^{*} \mathrm{f}_{\mathrm{u}} ; \mathrm{CL}_{\mathrm{i}}=\right.$ drug intrinsic clearance, $\mathrm{f}_{\mathrm{u}}$ : unbound drug fraction), while the clearance of the unbound drug depends solely on enzyme activity. $[25,26]$ Therefore, changes in the fraction bound to proteins (alpha ${ }_{1}$-acid glycoprotein) may affect the drug's total clearance but might also alter the relationship between total drug concentration and possible toxic effects. $[26,27,28]$ We did not measure alpha ${ }_{1}$ acid glycoprotein concentrations and to some extent this is a limitation of our study. However, the postoperative course of the patients included in our trial did Formatted: Not Superscript/ Subscript

\begin{tabular}{l} 
Formatted: Not Superscript/ \\
Subscript \\
\hline Deleted: \\
\hline Deleted: \\
\hline
\end{tabular}
not exhibit any pathophysiological changes other than those expected in patients undergoing this type of surgical procedure.

In conclusion, we demonstrate that during continuous epidural infusion of ropivacaine there is a flip flop kinetic and that we have to avoid the acritical use of a drug's terminal half-life to predict the drug's accumulation rate. Furthermore, we found an equation that could correlate the ropivacaine clearance to age also during epidural continuous infusion. It will be necessary to perform other trials in order to improve ropivacaine dosage individualization on the basis of pharmacokinetic data of patients. 


\section{References}

1. McClellan KJ, Faulds D. Ropivacaine: an update of its use in regional anaesthesia. Drugs 2000, 60: 1065-93.

2. Allegri $M$, Delazzo MG, Grossi $P$, Borghi $B$. Efficacy of drugs in regional anesthesia: A review. Eu J Pain 2009; 3(2): 41-8.

3. Mather LE, Chang DH. Cardiotoxicity with modern local anaesthetics: is there a safer choice? Drugs 2001; 61: 333-42.

4. Groban L, Deal DD, Vernon JC, James RL, Butterworth J. Cardiac resuscitation after incremental overdosage with lidocaine, bupivacaine, and ropivacaine in anesthetized dogs. Anesth Analg 2001; 92: 37-43.

5. Knudsen K, Beckmann Suurkula M, Blomberg S, Sjövall J, Edvardsson N. Central nervous and cardiovascular effects of i.v. infusions of ropivacaine, bupivacaine and placebo in volunteers. $\mathrm{Br} \mathrm{J}$ Anaesth 1997; 78: 507-14.

6. Scott DB, Lee A, Fagan D, Bowler GMR, Bloomfield P, Lundh R. Acute toxicity of ropivacaine compared with that of bupivacaine. Anesth Analg 1989; 69: 563-9.

7. Knudsen K, Beckman M, Suurküla M, Blomberg S, Sjövall J, Edvardsson N: Central nervous and cardiovascular effects of i.v. infusions of ropivacaine, bupivacaine and placebo in volunteers. Br J Anaesth 1997; 78:507-14.

8. Jokinen MJ. The pharmacokinetics of ropivacaine in hepatic and renal insufficiency. Best Practice Research Clinical Anaesthesiol 2005; 19(2): 269-74.

9. Erichsen CJ, Sjovall J, Kehlet H, hedlund C, Arvidsson T. Pharmacokinetics and analgesic effect of ropivacaine during continous epidural infusion for postoperative pain relief. Anesthesiology 1996; 84(4): 834-42.

10.Lee A, Fagan D, Lamont M, Tucker GT, Halldin M, Scott DB: Disposition kinetics of ropivacaine in humans. Anesth Analg 1989; 69: 736-8.

11. Emanuelsson B-MK, Persson J, Alm C, Heller A, Gustafsson LL. Systemic absorption and block after epidural injection of ropivacaine in healthy volunteers. Anesthesiology 1997; 87: 1309-17.

12. SIMED P-PHARM user's guide. SIMED, Creteil, France 17, 1994.

13. Mentre $F$, Mallet A. Handling covariates in population pharmacokinetics. Int $J$ Biomed Comput 1994; 36: 25-33.

14..Morton CPJ,Bloomfield S, Magnusson A, Jozwiak A, McClure JH. Ropivacaine $0.75 \%$ for extradural anaesthesia in elective caesarean section: an open clinical and pharmacokinetic study in mother and neonate. $\mathrm{Br} \mathrm{J}$ Anaesth 1997; 79(1): 38.
Formatted: English (U.S.)

Formatted: English (U.S.) 
15. Emanuelsson B-MK, Persson J, Sandin S, Alm C, Gustafsson LL. Intraindividual and interindividual variability in the disposition of the local anesthetic ropivacaine in healthy subjects. Therap Drug Monitor 1997; 19: 126-31.

16. Hansen TG, llett KF, Lim SI, Reid C, Hackett LP, Bergesio: Pharmacokinetics and clinical efficacy of long-term epidural ropivacaine infusion in children. $\mathrm{Br} \mathrm{J}$ Anaesth 2000; 85: 347-53.

17. Emanuelsson B-MK, Zaric D, Nydahl PA, Axelsson K. Pharmacokinetics of ropivacaine and bupivacaine during 21 hours of continous epidural infusion in healthy male volunteers. Anesth Analg; 1995; 81: 1163-8.

18. Halldin MM, Bredberg E, Angelin B, Arvidsson T, Askemark Y, Elofsson S, Widman M. Metabolism and excretion of ropivacaine in humans. Drug Metab Dispos 1996; 24: 962-8.

19. Helton SH, Denson DD. Pharmacodynamics and pharmacokinetics of epidural ropivacaine in humans. Anesth Analg 1990; 70: 16-21.

20.PharmPK Discussion-Steady state and long half-life. PharmPK Discussion List Archive - PK2006542.html-2006.

21. Habre W, Bergesio R, Johnson C, Hackett P, Joyce D, Sims C. Pharmacokinetics of ropivacaine following caudal analgesia in children. Paediatr Anaesth 2000; 10: 143-7.

22. Sahin S, Benet LZ. The operational multiple dosing half-life: a key to defining drug accumulation in patients and to designing extended release dosage forms. Pharmaceutical Research 2008; 25(12): 2869-77.

23. Nicòlas J, Oltra D, Navarro-Fontestad C, Nicòlas N, Ramìrez F, Alòs M, Casabo VG. Population pharmacokinetics of ropivacaine and bupivacaine after locoregional administration as anesthetic in hip or knee replacement surgery. Annual Meeting of the Population Approach Group in Europe 2009;.Abstr 1571.

24. Simon MJG, Veering BT, Stienstra R, Van Kleef JW, Burm AGL. The effects of age on neural blockade and hemodynamic changes after epidural anesthesia with ropivacaine. Anesth Analg 2002; 94: 1325-30.

25. MacKichan JJ. Influence of protein binding and use of unbound (free) drug concentrations. Applied Pharmacokinetics- Principles of Therapeutic Drug Monitoring. In Applied Therapeutics III edition 1992; Chapter 5.

26. Wiedemann D, Mühlnickel B, Staroske E, Neumann W, Röse Ropivacaine plasma concentrations during 120-hour epidural infusion. Br J Anaesth. 2000; 85(6): 830-5.

27. Hansen TG, llett KF, Reid C, Lim SI, Hackett LP, Bergesio R. Caudal ropivacaine in infants: population pharmacokinetics and plasma concentrations. Anesthesiology 2001; 94: 579-84.

28. Bleckner LL, Bina S, Kwon KH, McKnight G, Dragovich A, Buckenmaier CC. Serum Ropivacaine Concentrations and Systemic Local Anesthetic Toxicity in 
Trauma Patients Receiving Long-Term Continuous Peripheral Nerve Block Catheters. Anesth Analg 2010; 110: 630-4. 
Table I. Total plasma ropivacaine concentrations (geometric mean, geometric coefficient of variation (\%))at different time points during epidural infusion (ropivacaine $10 \mathrm{mg} / \mathrm{h}$ ) preceded by 2 sequential boluses of $10 \mathrm{mg}$ each.

\begin{tabular}{|l|c|c|c|}
\hline PK parameter & Unit & $\begin{array}{c}\text { Geometric } \\
\text { Mean }\end{array}$ & $\begin{array}{c}\text { Geometric } \\
\text { coefficient of } \\
\text { variation (\%) }\end{array}$ \\
\hline $\mathrm{C}_{0 \mathrm{~h}}$ & $\mu \mathrm{g} / \mathrm{mL}$ & 0.00 & 0.00 \\
\hline $\mathrm{C}_{3 \mathrm{~h}}$ & $\mu \mathrm{g} / \mathrm{mL}$ & 0.40 & 87.7 \\
\hline $\mathrm{C}_{6 \mathrm{~h}}$ & $\mu \mathrm{g} / \mathrm{mL}$ & 0.59 & 56.1 \\
\hline $\mathrm{C}_{12 \mathrm{~h}}$ & $\mu \mathrm{g} / \mathrm{mL}$ & 0.88 & 31.5 \\
\hline $\mathrm{C}_{24 \mathrm{~h}}$ & $\mu \mathrm{g} / \mathrm{mL}$ & 1.22 & 20.6 \\
\hline $\mathrm{C}_{48 \mathrm{~h}}$ & $\mu \mathrm{g} / \mathrm{mL}$ & 1.60 & 3.1 \\
\hline $\mathrm{C}_{54 \mathrm{~h}}$ & $\mu \mathrm{g} / \mathrm{mL}$ & 0.81 & 8.5 \\
\hline $\mathrm{C}_{60 \mathrm{~h}}$ & $\mu \mathrm{g} / \mathrm{mL}$ & 0.56 & 39.5 \\
\hline $\mathrm{C}_{3 \mathrm{~h}} / \mathrm{C}_{48 \mathrm{~h}}$ & - & 0.25 & 28.3 \\
\hline $\mathrm{C}_{12 \mathrm{~h}} / \mathrm{C}_{48 \mathrm{~h}}$ & - & 0.55 & 10.2 \\
\hline $\mathrm{C}_{24 \mathrm{~h}} / \mathrm{C}_{48 \mathrm{~h}}$ & - & 0.76 & 6.6 \\
\hline $\mathrm{C}_{\mathrm{max}}$ & $\mu \mathrm{g} / \mathrm{mL}$ & 1.82 & 2.9 \\
\hline $\mathrm{t}_{\mathrm{max}}$ & $\mathrm{hours}$ & 43 & 2.4 \\
\hline $\mathrm{AUC}_{(0-60 \mathrm{~h}}$ & $\mu \mathrm{g} \cdot \mathrm{h} / \mathrm{mL}$ & 67.48 & 2.2 \\
\hline $\mathrm{CL}_{2}(\mathrm{D} / \mathrm{AUC}$ & $\mathrm{L} / \mathrm{h}$ & 6.96 & 8.6 \\
\hline & & & \\
\hline
\end{tabular}


Table II - Ropivacaine population pharmacokinetic results

\begin{tabular}{||l||c||c||c|}
\hline Parameter & Unit & Mean & $\begin{array}{c}\text { Percent Coefficient of } \\
\text { Variation }\end{array}$ \\
\hline $\begin{array}{l}\text { Apparent Clearance } \\
(\mathrm{CL} / \mathrm{F})\end{array}$ & $\mathrm{L} / \mathrm{h}$ & 5.33 & 21.69 \\
\hline $\begin{array}{l}\text { Apparent Volume of } \\
\text { Distribution (Vd/F) }\end{array}$ & $\mathrm{L}$ & 92.15 & 16.42 \\
\hline
\end{tabular}

Values are mean (percent coefficient of variation) 


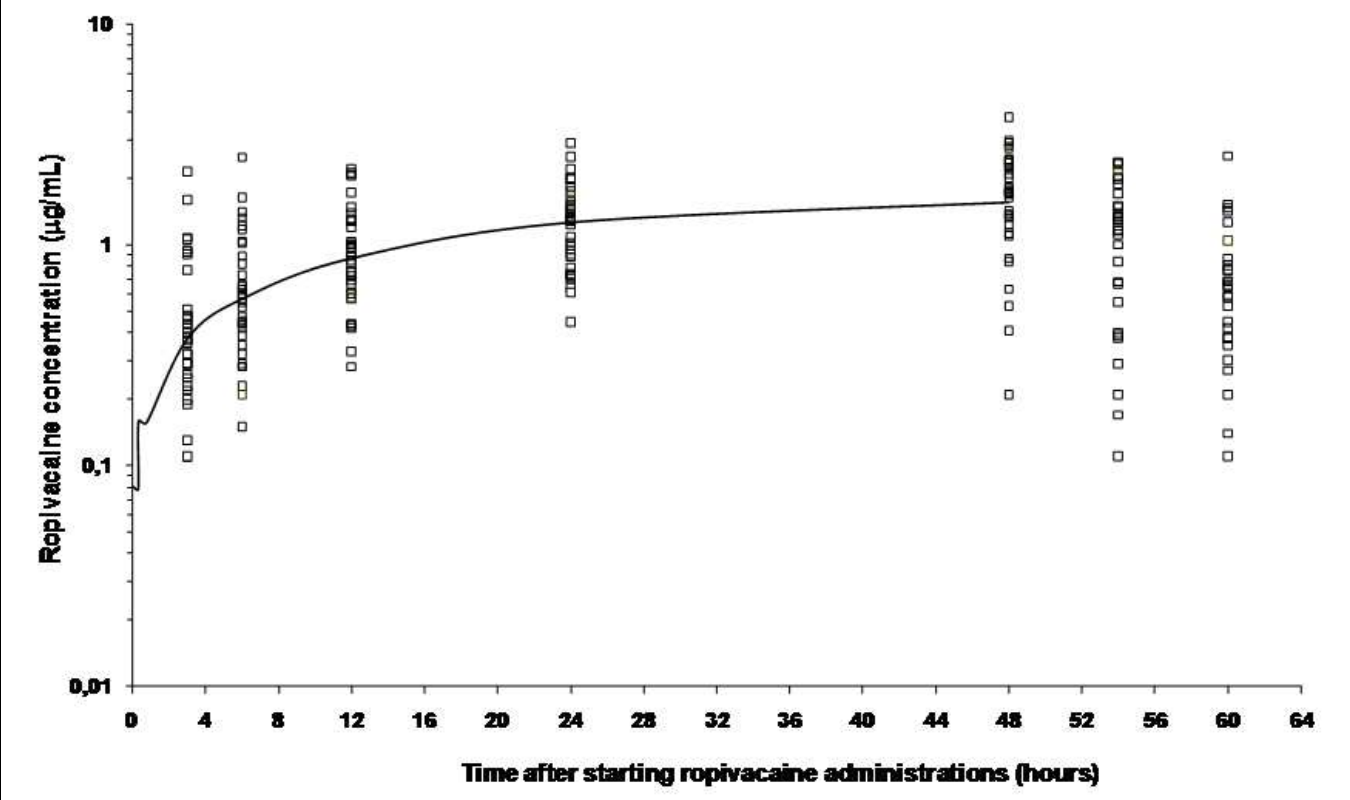

Figure 1. Total plasma ropivacaine concentration versus time during and after an* epidural continous infusion of $10 \mathrm{mg} /$ hour preceeded by 2 sequential epidural boluses. The solid line shows the computer-generated line of the best fit up to $48 \mathrm{~h}$, for a one-compartment model with zero-order input and first-order elimination.

$$
\mid \begin{aligned}
& \mid \\
& \mid
\end{aligned}
$$




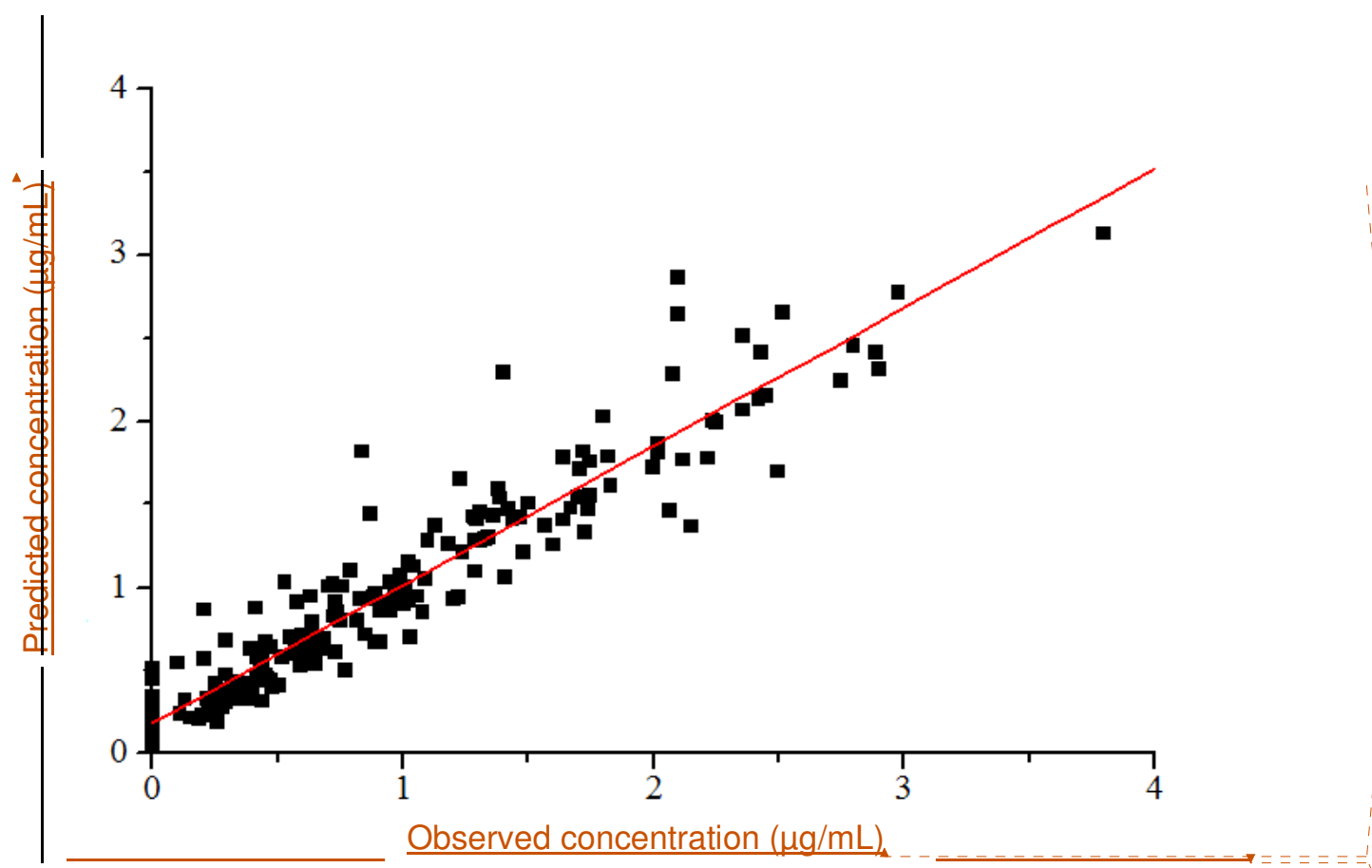

Figure 2. Scatterplot of estimated versus measured serum concentrations, in micrograms per milliliter, based on_jndividual patient Bayesian posteriori parameter distributions. Pooled data of all 43 patients.

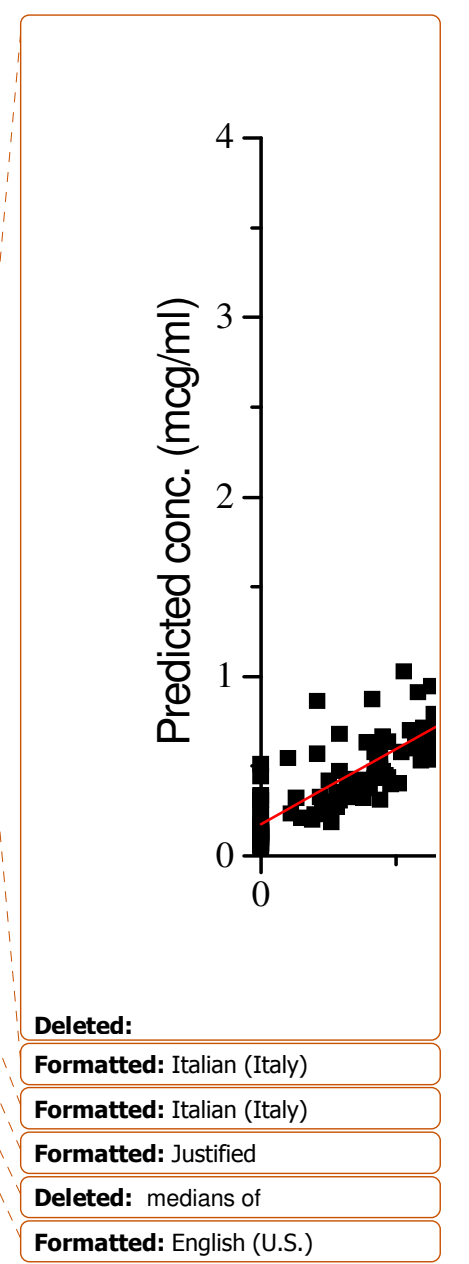




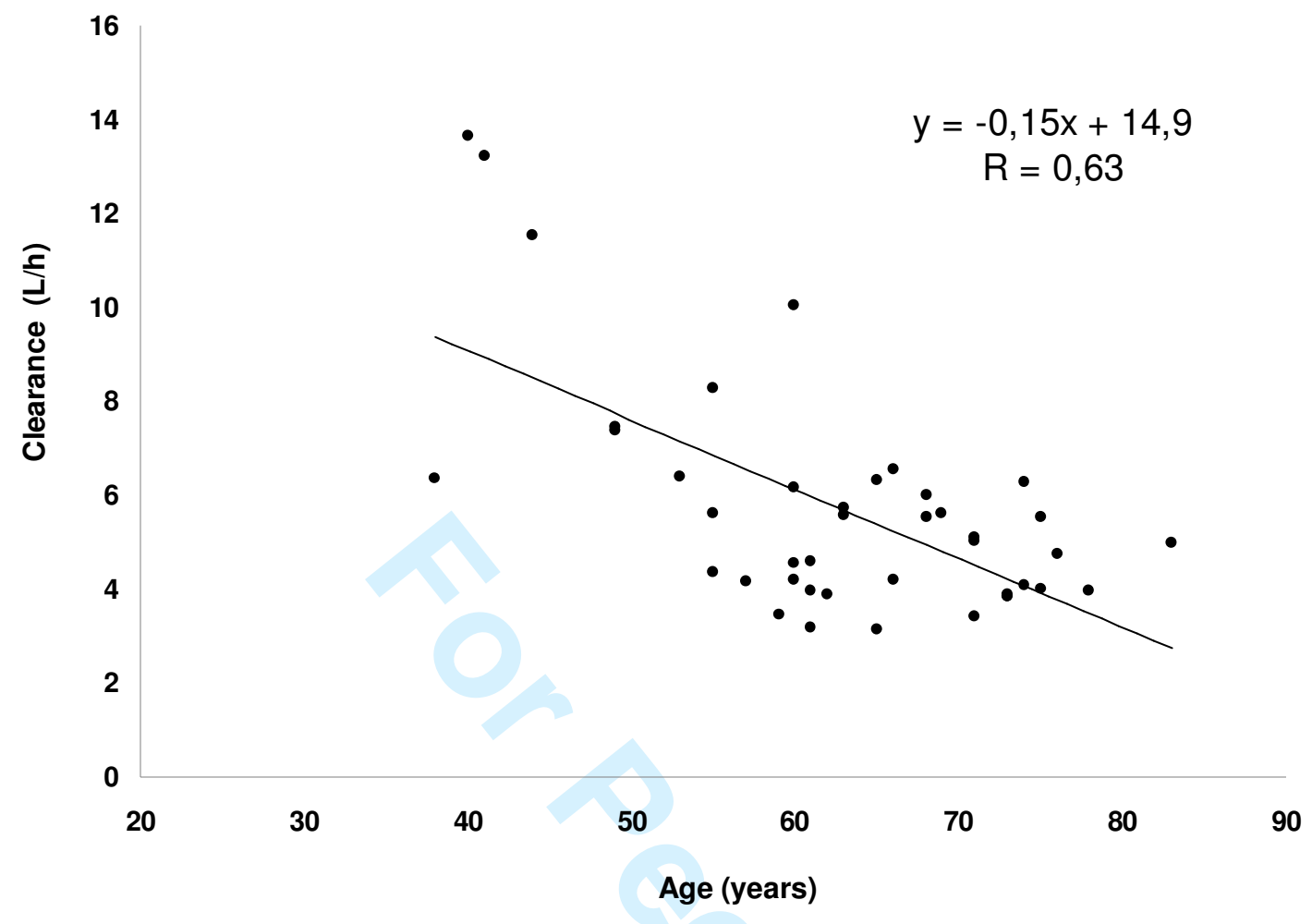

Fig 3. Relationship between ropivacaine total clearance (L/h) and age (years) 


\section{FLIP-FLOP KINETICS OF ROPIVACAINE DURING CONTINUOUS EPIDURAL INFUSION INFLUENCES ITS ACCUMULATION RATE}

Cusato $M^{1}$, Allegri $M^{2}$, Niebel $T^{2,3}$, Ingelmo $P^{4}$, Broglia $M^{1}$, Braschi $A^{2,5}$, Regazzi $M^{1}{ }^{1}$

${ }^{1}$ Laboratory of Clinical Pharmacokinetics, Foundation IRCCS Policlinico San Matteo, Pavia, Italy;

${ }^{2}$ Department of Anesthesia and Intensive Care I and Pain Therapy, Foundation IRCCS Policlinico San Matteo, Pavia, Italy;

${ }^{3}$ Department of Surgical Science- Pavia's University, Pavia, Italy;

${ }^{4}$ First Service of Anesthesia and Intensive Care San Gerardo Hospital Monza (MI) Department of Experimental Medicine Milan Bicocca's University, Milan, Italy;

${ }^{5}$ Department of Resuscitation and Organ Transplantation Surgery Sciences, Section of Anesthesiology and Resuscitation, University of Pavia

Correspondence to:

Dr. Mario Regazzi

Head of Laboratory of Clinical Pharmacokinetics

Foundation IRCCS Policlinico San Matteo

P.le Golgi, 2

I - 27100 Pavia

Italy

Tel. +390382503471

Fax +390382 422701

e-mail address: regazzim@smatteo.pv.it

\section{Acknowledgements:}

This research is supported by a grant of Scientific Direction of Fondazione IRCCS Policlinico San Matteo, Pavia, Italy. 
Abstract

Background

Ropivacaine has an optimal toxicity profile for epidural anesthesia in adults, but there are currently no studies concerning its pharmacokinetics during continuous infusion. The primary objective of this study was to evaluate the pharmacokinetics and safety of ropivacaine in adults during a 48-hours continuous epidural infusion.

\section{Materials and methods}

We enrolled 43 adults (ASA I-II) scheduled for major abdominal or urologic surgery with postoperative continuous epidural analgesia with ropivacaine $0.2 \%(5 \mathrm{~mL} / \mathrm{h})$ and sufentanil $0.75 \mu \mathrm{g} / \mathrm{mL}$ for 48 hours.

Ropivacaine blood samples were collected, during continuous epidural infusion, before the bolus and 3, 6, 12, 24, 48, 54, 60 hours after the bolus; plasma concentrations were measured on HPLC-UV. The concentration-time relationship of ropivacaine levels was analyzed using a population pharmacokinetic method based on a mixed-effect-model approach (P-PHARM software).

\section{Results}

Mean plasma concentration of ropivacaine at the end of epidural infusion $\left(\mathrm{C}_{48 \mathrm{~h}}\right)$ was $1.69 \mu \mathrm{g} / \mathrm{mL}(0.21-3.8 \mu \mathrm{g} / \mathrm{mL})$. Mean (range) $\mathrm{C}_{\max }$, was $1.82 \mu \mathrm{g} / \mathrm{L}(0.61-4.0 \mu \mathrm{g} / \mathrm{mL})$; the area under the plasma concentration curve, AUC (0-60), was $67.48 \pm 30.60 \mu \mathrm{g} . \mathrm{h} / \mathrm{mL}$.

Total plasma ropivacaine concentrations fell mainly within (84\%) or below (12\%) the range reported to be safe in adults $(1.0-3.0 \mu \mathrm{g} / \mathrm{mL})$. Only 2 patients $(5 \%)$ reached ropivacaine plasma levels higher than $3 \mu \mathrm{g} / \mathrm{mL}$, namely 3.8 and $4.0 \mu \mathrm{g} / \mathrm{mL}$ at 48 and 54 hours, respectively. Total ropivacaine concentrations up to $4.0 \mu \mathrm{g} / \mathrm{mL}$ were tolerated during long-term epidural ropivacaine infusion.

Mean clearance for total ropivacaine was $5.33 \mathrm{~L} / \mathrm{h}$. Age was the only covariable to significantly reduce clearance variability: $C L(L / h)=15.04-0.148$ * age (years). The volume of distribution $(\mathrm{Vd})$ was $92.15 \mathrm{~L}$. The infusion dosing period half-life $\left(\mathrm{t}_{1 / 2, \mathrm{DP}}=\right.$ 0.693 * $\mathrm{Vd} / \mathrm{CL}$ ) was 10.8 hours.

\section{Conclusions}

Exposure to ropivacaine during epidural infusion is highly variable. The apparent infusion dosing half-life $t_{1 / 2, D P}$ is the most appropriate parameter to predict drug 
accumulation upon epidural infusion since it appears to better reflect the interplay interference between volume distribution and absorption rate during the accumulation phase. Prediction of ropivacaine accumulation can be improved by considering patient age. 


\section{Introduction}

Ropivacaine (RPV) is a long-acting amide-type local anesthetic with a similar structure to bupivacaine [1]. Many literature studies have demonstrated the clinical efficacy of ropivacaine $0.2 \%$ epidural infusion, with only some individual case reports of major side-effects. [2,3,4,5] Although ropivacaine is a safer alternative to bupivacaine, excessive plasma concentrations of ropivacaine can cause severe central nervous system and cardiac toxicity. After epidural administration, both the systemic absorption and the systemic disposition of ropivacaine play an important role in determining the clinical profile and the risk of systemic toxicity. $[6,7,8,9]$

Ropivacaine calculated terminal half-life is significantly longer after epidural than after intravenous administration. Ropivacaine absorption after epidural administration cannot be derived directly from plasma concentration-time curves because of flip-flop kinetics. $[9,10]$ The flip-flop model implies slow absorption of ropivacaine from the epidural space into the systemic circulation rate-limits drug elimination. Therefore, when the process of absorption is a limiting factor, the terminal half-life reflects the rate and the extent of absorption and not the elimination process. $[10,11]$ In a system consisting of a series of processes, the decrease in concentrations after administration is discontinued and the time to reach the steady-state depends on the slowest process in the chain. This has implication for designing epidural continuous infusion schedules of ropivacaine, considering the clinical significance of accumulation reaching either toxic or ineffective concentrations.

The primary goal of this study was to evaluate the pharmacokinetics of ropivacaine accumulation in adults receiving continuous epidural analgesia during the first $48 \mathrm{~h}$ after major surgery. 


\section{Material and methods}

After approval from the Ethics Committee of San Matteo Hospital (EudraCT number 2010-019393-32) and written informed consent 49 adult patients, ASA class I-II, scheduled for major abdominal or urological surgery and planned to receive a postoperative epidural infusion after surgery for pain control were enrolled. Exclusion criteria were emergency surgery, coagulopathy, renal, hepatic, neurological or psychiatric diseases, a history of peripheral neuropathies and chronic opioid therapy.

Before anesthesia induction epidural catheter was positioned in sitting position, using the loss resistance technique. In patients scheduled for upper abdominal surgery the epidural catheter was placed between T7-T8 or T9-T10. In patients scheduled for lower abdominal or urologic surgery between T10-T11. General anesthesia was induced with Propofol $2 \mathrm{mg} / \mathrm{kg}$, Fentanyl $2 \mu \mathrm{g} / \mathrm{kg}$, Cisatracurium $0.15 \mathrm{mg} / \mathrm{kg}$, and was maintained with Fentanyl and Sevoflurane 2\%. Forty five minutes before the end of surgery patients received an epidural loading dose (RPV $0.2 \% 5 \mathrm{ml}+$ Sufentanil $10 \mu \mathrm{g}$ ), followed by a second bolus (RPV 02\% $5 \mathrm{ml}$ ) 15 minutes later. At the end of surgery an epidural infusion of Ropivacaine $0.2 \%$ plus Sufentanil $0.8 \mu \mathrm{g} / \mathrm{ml}$ was started. Ropivacaine/Sulfentanyl epidural infusion was constantly condelivered at a rate of $5 \mathrm{ml} / \mathrm{h}$ using an electronic infusion pump during the first $48 \mathrm{hs}$ after surgery.

Patients were evaluated every 6 hours during the first day after surgery and every 12 hours in the second postoperative day. We recorded vital signs (arterial pressure and heart rate), pain according to the Numeric Rate Scale (at rest - NRS - and after movement -mNRS-), analgesic rescue dose (administered if NRS $>4$ ), Holmen scale (to assess if there was sensory block), sedation scale and clinical side-effects (nausea, vomiting, itching, hypotension, systemic neurological side effects)

\section{Reagents}

RPV was a gift of the Department of Anesthesia and Intensive Care. Phenacetin was purchased from Sigma (St. Louis, MO, USA). All other chemicals and reagents used were of the highest commercially available quality.

Instrumentation 
The HPLC system consisted of Varian Prostar Mod.430 a pump equipped with variable-wavelength UV detector (Varian Prostar Mod.330). Separation was achieved using a reverse-phase C-18 column $(250 \times 4.6 \mathrm{~mm}$ I.D., particle size $5 \mu \mathrm{m}$, Hypersil BDS-CPS Analitica, Italy). The mobile phase was acetonitrile-methanol-50mM potassium dihydrogen phosphate $(\mathrm{pH}=6)(180: 160: 660, \mathrm{v} / \mathrm{v} / \mathrm{v})$ delivered at a flow rate of $1.3 \mathrm{~mL} / \mathrm{min}$. Chromatographic separation was performed at laboratory room temperature and monitored at $210 \mathrm{~nm}$.

The HPLC method has been validated over the range 0.1-4 $\mu \mathrm{g} / \mathrm{mL}$. The assay was linear over the entire concentration range $\left(r^{2}=0.99\right)$. Intra- and inter-day precision and accuracy was less than $6 \%$.

The limit of detection (LOD) was $0.050 \mu \mathrm{g} / \mathrm{mL}$, the limit of quantification (LOQ) was 0.1 $\mu \mathrm{g} / \mathrm{mL}$.

Preparation of Standard solution and standard curves

A standard stock solution $(1 \mathrm{mg} / \mathrm{mL})$ of drug was prepared in methanol-water (50/50), stored at $-20^{\circ} \mathrm{C}$ and were stable for at least 6 months. Plasma standards and controls were prepared at concentrations of $0.1,0.2,0.4,1.0,2.0,4.0 \mu \mathrm{g} / \mathrm{mL}$ and 0.12 (Low), 0.8 (Medium) and 1.6 (High) $\mu \mathrm{g} / \mathrm{mL}$, respectively, by diluting appropriate aliquots of the stock solution with drug-free serum. The calibration curve was obtained by linear regression of the peak-height ratios of ropivacaine to the internal standard and plotting these against the nominal concentration of the drug.

Blood sampling

Blood samples were obtained immediately before bolus drug administration and 3, 6 , $12,24,48,54$ and $60 \mathrm{~h}$ after starting the infusion. Plasma was separated by centrifugation, transferred to clean prelabeled tubes and frozen at $-20^{\circ} \mathrm{C}$ until analysis. Sample preparation

$250 \mu \mathrm{L}$ of distilled deionized water,500 $\mu \mathrm{L}$ of dichloromethane and $10 \mu \mathrm{L}$ phenacetin (10 $\mu \mathrm{g} / \mathrm{mL}$, I.S.) were added to $250 \mu \mathrm{L}$ of plasma. After vortex mixing for 3 minutes, the tubes were centrifuged at $1200 \mathrm{~g}$ for $10 \mathrm{~min}$. The organic phase was transferred into a clean conical tube and evaporated to dryness under a gentle nitrogen stream. The residue was dissolved in $200 \mu \mathrm{L}$ mobile phase and $50 \mu \mathrm{L}$ was injected into HPLC. 


\section{Pharmacokinetic analysis}

The concentration-time relationship of ropivacaine levels (corresponding to 6 data points) during an epidural infusion preceded by 2 sequential boluses was analyzed using a population pharmacokinetic method based on a mixed-effect-model approach. This method separates explicitly the variability of drug concentrations in the population into two parts: interindividual variability characterized by the distribution of pharmacokinetic parameters in the population and residual variability (e.g., measurement errors). A parametric approach $[12,13]$ was used (using the P-PHARM software, which is now incorporated into the Innaphase Kinetica suite) to estimate the mean and interindividual variance of each pharmacokinetic parameter in the population, to calculate the Bayesian maximum a posteriori estimates of individual pharmacokinetic parameters, and to test the relationships between these individual estimates and several covariates (gender, age, body weight, height, renal and hepatic function indices). During covariate modeling, P-PHARM can automatically search for a linear relationship between covariates and the population parameter estimates.

Pharmacokinetic data were fitted with different compartmental models. The most appropriate model was chosen based on the Akaike information criterion [12] and the examination of residual plots. A one-compartment model with sequential bolus and infusion inputs was fitted to the total plasma ropivacaine concentration-time data.

The plasma concentration versus time curve of ropivacaine during continuous epidural infusion ( $\mathrm{R}_{0}$ : rate of epidural infusion) was described by the equation:

$$
\mathrm{C}=\left(\mathrm{R}_{0} / \mathrm{CL}\right) \cdot\left(1-\mathrm{e}^{-\lambda} \mathrm{DP} \cdot \mathrm{t}^{\mathrm{t}}\right)
$$

$\lambda_{\mathrm{DP}}$ indicates the "mixed" (absorption/distribution/elimination) rate constant of ropivacaine observed during 48-hour epidural drug administration and calculated by the $\mathrm{CL} / \mathrm{Vd}$ ratio. $\mathrm{t}_{1 / 2, \mathrm{DP}}$ was defined as the $0.693 / \lambda_{\mathrm{DP}}$ ratio and represents the infusion dosing half-life.

Ropivacaine pharmacokinetic starting estimates for the population analysis were obtained from previous studies. A heteroscedastic error variance $(1 / \mathrm{Y})$ model was used to describe residual error, and a log-normal distribution was used to describe 
interpatient variability in apparent clearance $(\mathrm{CL})$ and apparent volume of distribution $(\mathrm{Vd})$.

When bioavailability $(F)$ is not known, estimates of $C L$ should be related to $F$, i.e., CL/F. Bioavailability was fixed to 1 , assuming total (100\%) absorption after epidural administration. Model evaluation was conducted as recommended in the P-PHARM manual and also by examination of a plot of measured/predicted concentration data versus time.

After the end of infusion, the terminal rate constant $(\lambda$,terminal $)$ was determined for total ropivacaine by linear regression of the last 3 data points on the plasma concentrationtime curve (from the $48^{\text {th }}$ hour to the $60^{\text {th }}$ hour):

$$
C^{\prime}=C_{48 h} \cdot e^{-\lambda} \text { terminal } \cdot t^{\prime}
$$

$t_{1 / 2 \text {,terminal }}$ was defined as the $0.693 / \lambda_{\text {terminal }}$ ratio and represents the terminal half-life after the infusion is stopped. $t$ ' is the time since the end of the infusion.

The area under the plasma concentration time curve was calculated by numeric integration using the linear trapezoidal rule. $\mathrm{C}_{\max }$ was the highest concentration achieved; the time to $C_{\max }$ and the plasma concentrations at 3, 6, 12, 24, 48, 54 and 60 $h$ after starting ropivacaine administration $\left(\mathrm{C}_{3 \mathrm{~h}}, \mathrm{C}_{6 \mathrm{~h}}, \mathrm{C}_{12 \mathrm{~h}}, \mathrm{C}_{24 \mathrm{~h}}, \mathrm{C}_{48 \mathrm{~h}}, \mathrm{C}_{54 \mathrm{~h}}, \mathrm{C}_{60 \mathrm{~h}}\right.$, respectively) were derived directly from ropivacaine levels.

\section{Statistical analysis}

Patient characteristics are summarized as median values (range). Total plasma ropivacaine concentrations and derived pharmacokinetic data are summarized as geometric mean (geometric coefficient of variation, CV\%) and/or mean $( \pm S D)$ values. Multiple-linear regression analysis with stepwise inclusion between maximum $a$ posteriori estimates of all pharmacokinetic parameters and all covariates was performed with the analysis of variance to determine the relevant relationships (with the P-PHARM software). [12] A value of $P<0.05$ was considered significant. 


\section{Results}

Forty-nine adults consecutive were enrolled and six were excluded after discontinuation of epidural continuous infusion because of clinical or hemodynamic problems not related to ropivacaine epidural infusion; data collection was incomplete in one other patient, whose data were nevertheless included in our PK analysis. Forty-three patients completed the analysis.

Thirty-five patients underwent major abdominal surgery and eight underwent urological surgery (29 males and 14 females). Patient age ranged from 41 to 83 years (median=63 years) and body weight ranged from 50 to $100 \mathrm{~kg}$ (median= $75.5 \mathrm{~kg}$ ).

Analgesia was satisfactory in all cases and there were no cardiocirculatory side-effects, such as major hypotension or arrhythmia, which could require discontinuation of the epidural infusion. There were no minor (facial dysthesia, tinnitus, changes in sensitivity and strength) or major (convulsions, hallucinations) neurological complications during continuous epidural infusion of ropivacaine.

A total of 330 plasma concentrations from 43 patients were used to compute pharmacokinetic parameters including a baseline sample, four samples collected during ropivacaine infusion and three samples collected during the first $12 \mathrm{~h}$ after ropivacaine infusion discontinuation.

Pharmacokinetic data (geometric mean and geometric coefficient of variation, CV\%) are summarized in Table I.

During the epidural infusion (ropivacaine $10 \mathrm{mg} / \mathrm{h}$ ) preceded by 2 sequential boluses of $10 \mathrm{mg}$ each, plasma concentrations of ropivacaine leveled off, as expected. Exposure to ropivacaine during epidural infusion was highly variable.

The plasma concentration of ropivacaine at the end of epidural infusion $\left(\mathrm{C}_{48 \mathrm{~h}}\right)$ was 1.60 $\pm 0.89 \mu \mathrm{g} / \mathrm{mL}$. After 12 hours and 24 hours, respectively, $\sim 50 \%$ and $\sim 75 \%$ of the 48 hour level of ropivacaine were reached. $C_{\max }$, was $1.82 \pm 0.89 \mu \mathrm{g} / \mathrm{L}$ and was observed at a mean time $\left(t_{\max }\right)$ of 48 hours.

Total plasma ropivacaine concentrations were mainly within (84\%) or below (12\%) the range reported to be safe in adults $(1.0-3.00 \mu \mathrm{g} / \mathrm{mL})$. [5,6, 9, 14,15,16] Only 2 patients $(5 \%)$ reached ropivacaine plasma levels higher than $3.0 \mu \mathrm{g} / \mathrm{mL}$, namely 3.8 and 4.0 
$\mu \mathrm{g} / \mathrm{mL}$ at 48 and 54 hours, respectively. Total ropivacaine concentrations up to 4.0 $\mu \mathrm{g} / \mathrm{mL}$ were tolerated during long-term epidural ropivacaine infusion.

Figure 1 shows all the measured plasma ropivacaine concentrations and the drug concentration-time curve resulting from the average population parameters estimated with P-Pharm.

Estimated population characteristics of the kinetic parameters together for ropivacaine clearance $(\mathrm{CL})$ and the apparent volume of distribution $(\mathrm{Vd})$ with their coefficient of variation are presented in Table II.

The dosing period absorption/distribution/elimination rate constant of ropivacaine calculated by the average population parameters $\left(\lambda_{\mathrm{DP}}=\mathrm{CL} / \mathrm{Vd}\right)$ was $0.064 \mathrm{~h}^{-1}$ and the corresponding $\mathrm{t}_{1 / 2, \mathrm{DP}}=\left(0.693^{*} \mathrm{Vd}\right) / \mathrm{CL}=10.8$ hours.

Following the end of epidural infusion of ropivacaine, the terminal half-life $\left(\mathrm{t}_{1 / 2, \text { terminal }}\right)$, determined for total ropivacaine by linear regression of the last 3 data points on the plasma concentration-time curve was 7.4 hours.

The pharmacokinetic population parameters were subsequently used to fit the concentration data up to $48 \mathrm{~h}$ using the Bayesian estimation method. This procedure enables the estimation of individual pharmacokinetic parameters for ropivacaine. The individual posterior Bayesian estimates of ropivacaine pharmacokinetic parameters were generated using a maximum a posteriori probability Bayesian fitting procedure. ${ }^{23}$ ] The performance of individualized Bayesian estimation steps is shown in the plots of the observed versus estimated plasma concentrations in Figure 2, and by the frequency distribution histogram of the normalized residuals which revealed a distribution very close to the expected one (normal with zero mean and unitary variance).

Through covariate analysis, we found that age was the only independent predictor identified.

In fact, the stepwise inclusion performed on P-PHARM revealed an age effect on CL, which explains $39.8 \%$ of the interindividual variability of the population pharmacokinetic parameters. Ropivacaine clearance correlated inversely with age. The linear correlation between age and ropivacaine clearance was best described by the equation (least square regression; $r=0.63, p<0.001$ ): 


$$
C L(L / h)=14.9-0.15 . \text { age }(\text { years })
$$




\section{Discussion}

Pharmacokinetic of epidural ropivacaine was well described after single dose, but it was important to detect what it can happen during continuous infusion. Whereby we investigated which kind of kinetic we have during epidural continuous infusion and if there are predictors that can determine a change in the pharmacokinetic profile.

In fact, plasma concentration profiles and the potential risk of systemic toxicity after epidural administration of ropivacaine depends on the administered dose and the interaction between the rate processes involved in drug absorption and systemic disposition. $[2,16,17,18,19]$ Unfortunately, absorption and disposition kinetics cannot be derived directly from the plasma concentration-time profile, since local anesthetics exhibit flip-flop kinetics after epidural administration. In a system consisting of a series of processes or compartments, not only the decrease in the concentrations after stopping administration but also the time to reach steady-state depend on the slowest process in the chain.

Half-life is the most clinically relevant pharmacokinetic parameter to predict drug accumulation time in a patient upon constant rate administration. Problems arise when we have to pick the half-life upon which to calculate drug accumulation. Also, when estimating the time for the epidural administration to achieve steady-state, we have to decide if we should work with the actual elimination half-life of ropivacaine obtained from the $\mathrm{PK}$ of the intravenous formulation $\left(\mathrm{t}_{1 / 2, \mathrm{IV}}\right)$, consider the terminal half-life calculated after the end of the infusion ( $\mathrm{t}_{1 / 2, \text { terminal }}$ ), or take into account the "mixed" absorption/distribution/elimination half-life estimated during the epidural infusion $\left(\mathrm{t}_{1 / 2, \mathrm{DP})}\right.$.

When the process of absorption is not a limiting factor, half-life is a hybrid parameter controlled by plasma clearance and extent of distribution. When the process of absorption is a limiting factor, the terminal half-life reflects mainly the rate and extent of absorption and not the elimination process (flip-flop pharmacokinetics). [20] Our data indicate that the true half-life of ropivacaine, as reported after IV administration ( $t_{1 / 2, I V}$ $1.8 \pm 0.7$ hours) [21], is irrelevant to the time to reach steady-state. 
In order to predict drug accumulation upon epidural infusion dosing, it is more appropriate to use the apparent infusion dosing half-life $t_{1 / 2, D P}$ since this parameter appears to better reflect the interplay interference between volume distribution and absorption rate during the accumulation phase. Our data indicate that this infusion dosing period half-life ( $\mathrm{t}_{1 / 2 \mathrm{DP}}=10.8$ hours) was higher $(\uparrow 45 \%)$ than the terminal half-life $\left(t_{1 / 2 t e r m i n a l}=7.4\right.$ hours $)$; a more pronounced sensitivity of the $t_{1 / 2 D P}$ to the absorption rate process probably explains the difference. This difference seems to confirm the indication by Sahin and Benet [22] to avoid the acritical use of a drug's terminal half-life to predict the drug's accumulation rate.

A one-compartment model with zero-order input and first-order elimination was optimal for describing the data in the accumulation phase during epidural infusion of ropivacaine. The same model was used by Hansen et al. [16] to describe the trend of ropivacaine concentrations during the accumulation phase in pediatric patients (mean age: 3.3 years, range: 0.3-7.3 years) under continuous epidural infusion. In the majority of children ropivacaine concentrations had reached the steady-state within 36 hours and the half life $\left(t_{1 / 2 D P}\right)$ of total ropivacaine was 4.9 hours. The apparent total clearance $(0.51 \mathrm{~L} / \mathrm{h} / \mathrm{kg})$ and the apparent volume of distribution $(3.1 \mathrm{~L} / \mathrm{kg})$ were about six and three times the values obtained in our adult patients, respectively. The pharmacokinetic parameters obtained in our study from data following continuous epidural infusion are different from the corresponding values reported after IV administration (Vd: 88.8L vs. 41.7L, CL: $5.7 \mathrm{~L} / \mathrm{h}$ vs. $23.2 \mathrm{~L} / \mathrm{h}$ ) in adult patients. On the other hand, the final parameters of ropivacaine obtained by a population pharmacokinetic analysis [23] (NONMEN) after loco-regional administration as an anesthetic in hip or knee replacement surgery were quite similar: the apparent clearance was $3.5 \mathrm{~L} / \mathrm{h}$ and the volume of distribution was 65.3L. When evaluating the individual pharmacokinetic parameters, though, we must keep in mind that modeling is always dangerous if no IV data are available, because we may get a good fit of data to our equations but the parameters are hybridized and therefore incorrect. It has been underlined that when one models with sums of exponentials, one can simply assume consistency (best to assume this for the equation and not the model). Thus, good fits do not validate our model but only indicate consistency. In most cases, like this one, it is not strictly necessary to assume 
validation [20]. Modeling with sums of exponentials is feasible, as long as the results are reported in terms of macroscopic parameters (coefficients and exponents) and model-independent parameters, such as mean systemic or oral clearance, which is always dose over AUC (Table II).

For a drug such as ropivacaine, the time to reach the steady-state may be influenced by the absorption rate (if administered by extravascular route), by the volume of distribution and by clearance; however, mean steady-state concentration depends only on clearance. Also, it is well recognized that clearance (divided by bioavailability) defines the appropriate rate of administration of a particular drug through the relationship: $R_{0}=C L . C_{s s, a v e}$.F. For ropivacaine $(10 \mathrm{mg} /$ hour), a drug following linear kinetics, the predicted concentration at steady-state, $\mathrm{C}_{\mathrm{ss} \text {,ave, }}$, based on individual a posteriori Bayesian estimates of ropivacaine pharmacokinetic clearance resulted in a mean value of $2.0( \pm 0.62) \mu \mathrm{g} / \mathrm{mL}$. At the end of infusion (48 $\mathrm{h}$ after the start of treatment) the ropivacaine plasma levels achieved corresponded on average to $\sim 90 \%$ of the levels that would be achieved at the steady-state.

Our data showed that prediction of ropivacaine accumulation can be improved by considering patient age. After epidural infusion, a trend towards a lower total plasma clearance with increasing age was observed (Fig.3). Simon et al.[24] studied the influence of age on pharmacokinetics of ropivacaine after single epidural administration and reported similar results: clearance is significantly decreased in the oldest patients relative to the youngest ones. In our study we confirmed that also during continuous infusion there is an inversely correlation between age and clearance. In fact RPV clearance in a 40-year-old individual is about twice as high as in a 70-year-old subject. As ropivacaine is extensively metabolized in the liver [8], the age dependence in clearance may presumably reflect decreased enzyme activity.

Studies during prolonged epidural infusion of ropivacaine showed that postoperative increases in plasma alpha ${ }_{1}$-acid glycoprotein concentrations are associated with increases in the plasma protein binding and in the total plasma concentrations of ropivacaine. Ropivacaine total clearance depends on liver enzyme activity and on the 
free drug fraction in plasma $\left(C L \sim \mathrm{CL}_{i}{ }^{*} \mathrm{f}_{\mathrm{u}} ; \mathrm{CL}_{\mathrm{i}}=\right.$ drug intrinsic clearance, $\mathrm{f}_{\mathrm{u}}$ : unbound drug fraction), while the clearance of the unbound drug depends solely on enzyme activity. [25,26] Therefore, changes in the fraction bound to proteins (alpha ${ }_{1}$-acid glycoprotein) may affect the drug's total clearance but might also alter the relationship between total drug concentration and possible toxic effects. $[26,27,28]$ We did not measure alpha ${ }_{1}$ acid glycoprotein concentrations and to some extent this is a limitation of our study. However, the postoperative course of the patients included in our trial did not exhibit any pathophysiological changes other than those expected in patients undergoing this type of surgical procedure.

In conclusion, we demonstrate that during continuous epidural infusion of ropivacaine there is a flip flop kinetic and that we have to avoid the acritical use of a drug's terminal half-life to predict the drug's accumulation rate. Furthermore, we found an equation that could correlate the ropivacaine clearance to age also during epidural continuous infusion. It will be necessary to perform other trials in order to improve ropivacaine dosage individualization on the basis of pharmacokinetic data of patients. 


\section{References}

1. McClellan KJ, Faulds D. Ropivacaine: an update of its use in regional anaesthesia. Drugs 2000, 60: 1065-93.

2. Allegri $M$, Delazzo MG, Grossi $P$, Borghi B. Efficacy of drugs in regional anesthesia: A review. Eu J Pain 2009; 3(2): 41-8.

3. Mather LE, Chang DH. Cardiotoxicity with modern local anaesthetics: is there a safer choice? Drugs 2001; 61: 333-42.

4. Groban L, Deal DD, Vernon JC, James RL, Butterworth J. Cardiac resuscitation after incremental overdosage with lidocaine, bupivacaine, and ropivacaine in anesthetized dogs. Anesth Analg 2001; 92: 37-43.

5. Knudsen K, Beckmann Suurkula M, Blomberg S, Sjövall J, Edvardsson N. Central nervous and cardiovascular effects of i.v. infusions of ropivacaine, bupivacaine and placebo in volunteers. $\mathrm{Br} \mathrm{J}$ Anaesth 1997; 78: 507-14.

6. Scott DB, Lee A, Fagan D, Bowler GMR, Bloomfield P, Lundh R. Acute toxicity of ropivacaine compared with that of bupivacaine. Anesth Analg 1989; 69: 563-9.

7. Knudsen K, Beckman M, Suurküla M, Blomberg S, Sjövall J, Edvardsson N: Central nervous and cardiovascular effects of i.v. infusions of ropivacaine, bupivacaine and placebo in volunteers. Br J Anaesth 1997; 78:507-14.

8. Jokinen MJ. The pharmacokinetics of ropivacaine in hepatic and renal insufficiency. Best Practice Research Clinical Anaesthesiol 2005; 19(2): 269-74.

9. Erichsen CJ, Sjovall J, Kehlet H, hedlund C, Arvidsson T. Pharmacokinetics and analgesic effect of ropivacaine during continous epidural infusion for postoperative pain relief. Anesthesiology 1996; 84(4): 834-42.

10. Lee A, Fagan D, Lamont M, Tucker GT, Halldin M, Scott DB: Disposition kinetics of ropivacaine in humans. Anesth Analg 1989; 69: 736-8.

11. Emanuelsson B-MK, Persson J, Alm C, Heller A, Gustafsson LL. Systemic absorption and block after epidural injection of ropivacaine in healthy volunteers. Anesthesiology 1997; 87: 1309-17.

12.SIMED P-PHARM user's guide. SIMED, Creteil, France 17, 1994.

13. Mentre $\mathrm{F}$, Mallet $\mathrm{A}$. Handling covariates in population pharmacokinetics. Int $\mathrm{J}$ Biomed Comput 1994; 36: 25-33.

14..Morton CPJ,Bloomfield S, Magnusson A, Jozwiak A, McClure JH. Ropivacaine $0.75 \%$ for extradural anaesthesia in elective caesarean section: an open clinical and pharmacokinetic study in mother and neonate. Br J Anaesth 1997; 79(1): 38.

15. Emanuelsson B-MK, Persson J, Sandin S, Alm C, Gustafsson LL. Intraindividual and interindividual variability in the disposition of the local anesthetic ropivacaine in healthy subjects. Therap Drug Monitor 1997; 19: 126-31. 
16. Hansen TG, llett KF, Lim SI, Reid C, Hackett LP, Bergesio: Pharmacokinetics and clinical efficacy of long-term epidural ropivacaine infusion in children. $\mathrm{Br} \mathrm{J}$ Anaesth 2000; 85: 347-53.

17.Emanuelsson B-MK, Zaric D, Nydahl PA, Axelsson K. Pharmacokinetics of ropivacaine and bupivacaine during 21 hours of continous epidural infusion in healthy male volunteers. Anesth Analg; 1995; 81: 1163-8.

18. Halldin MM, Bredberg E, Angelin B, Arvidsson T, Askemark Y, Elofsson S, Widman M. Metabolism and excretion of ropivacaine in humans. Drug Metab Dispos 1996; 24: 962-8.

19. Helton SH, Denson DD. Pharmacodynamics and pharmacokinetics of epidural ropivacaine in humans. Anesth Analg 1990; 70: 16-21.

20.PharmPK Discussion-Steady state and long half-life. PharmPK Discussion List Archive - PK2006542.html-2006.

21. Habre W, Bergesio R, Johnson C, Hackett P, Joyce D, Sims C. Pharmacokinetics of ropivacaine following caudal analgesia in children. Paediatr Anaesth 2000; 10: 143-7.

22. Sahin S, Benet LZ. The operational multiple dosing half-life: a key to defining drug accumulation in patients and to designing extended release dosage forms. Pharmaceutical Research 2008; 25(12): 2869-77.

23. Nicòlas J, Oltra D, Navarro-Fontestad C, Nicòlas N, Ramìrez F, Alòs M, Casabo VG. Population pharmacokinetics of ropivacaine and bupivacaine after locoregional administration as anesthetic in hip or knee replacement surgery. Annual Meeting of the Population Approach Group in Europe 2009;.Abstr 1571.

24. Simon MJG, Veering BT, Stienstra R, Van Kleef JW, Burm AGL. The effects of age on neural blockade and hemodynamic changes after epidural anesthesia with ropivacaine. Anesth Analg 2002; 94: 1325-30.

25. MacKichan JJ. Influence of protein binding and use of unbound (free) drug concentrations. Applied Pharmacokinetics- Principles of Therapeutic Drug Monitoring. In Applied Therapeutics III edition 1992; Chapter 5.

26. Wiedemann D, Mühlnickel B, Staroske E, Neumann W, Röse Ropivacaine plasma concentrations during 120-hour epidural infusion. Br J Anaesth. 2000; 85(6): 830-5.

27. Hansen TG, llett KF, Reid C, Lim SI, Hackett LP, Bergesio R. Caudal ropivacaine in infants: population pharmacokinetics and plasma concentrations. Anesthesiology 2001; 94: 579-84.

28. Bleckner LL, Bina S, Kwon KH, McKnight G, Dragovich A, Buckenmaier CC. Serum Ropivacaine Concentrations and Systemic Local Anesthetic Toxicity in Trauma Patients Receiving Long-Term Continuous Peripheral Nerve Block Catheters. Anesth Analg 2010; 110: 630-4. 
Table I. Total plasma ropivacaine concentrations (geometric mean, geometric coefficient of variation (\%))at different time points during epidural infusion (ropivacaine $10 \mathrm{mg} / \mathrm{h}$ ) preceded by 2 sequential boluses of $10 \mathrm{mg}$ each.

\begin{tabular}{|c|c|c|c|}
\hline PK parameter & Unit & $\begin{array}{c}\text { Geometric } \\
\text { Mean }\end{array}$ & $\begin{array}{c}\text { Geometric } \\
\text { coefficient of } \\
\text { variation (\%) }\end{array}$ \\
\hline $\mathrm{C}_{0 \mathrm{~h}}$ & $\mu \mathrm{g} / \mathrm{mL}$ & 0.00 & 0.00 \\
\hline $\mathrm{C}_{3 \mathrm{~h}}$ & $\mu \mathrm{g} / \mathrm{mL}$ & 0.40 & 87.7 \\
\hline $\mathrm{C}_{6 \mathrm{~h}}$ & $\mu \mathrm{g} / \mathrm{mL}$ & 0.59 & 56.1 \\
\hline $\mathrm{C}_{12 \mathrm{~h}}$ & $\mu \mathrm{g} / \mathrm{mL}$ & 0.88 & 31.5 \\
\hline $\mathrm{C}_{24 \mathrm{~h}}$ & $\mu \mathrm{g} / \mathrm{mL}$ & 1.22 & 20.6 \\
\hline $\mathrm{C}_{48 \mathrm{~h}}$ & $\mu \mathrm{g} / \mathrm{mL}$ & 1.60 & 3.1 \\
\hline $\mathrm{C}_{54 \mathrm{~h}}$ & $\mu \mathrm{g} / \mathrm{mL}$ & 0.81 & 8.5 \\
\hline $\mathrm{C}_{60 \mathrm{~h}}$ & $\mu \mathrm{g} / \mathrm{mL}$ & 0.56 & 39.5 \\
\hline $\mathrm{C}_{3 \mathrm{~h}} / \mathrm{C}_{48 \mathrm{~h}}$ & - & 0.25 & 28.3 \\
\hline $\mathrm{C}_{12 \mathrm{~h}} / \mathrm{C}_{48 \mathrm{~h}}$ & - & 0.55 & 10.2 \\
\hline $\mathrm{C}_{24 \mathrm{~h}} / \mathrm{C}_{48 \mathrm{~h}}$ & - & 0.76 & 6.6 \\
\hline $\mathrm{C}_{\max }$ & $\mu \mathrm{g} / \mathrm{mL}$ & 1.82 & 2.9 \\
\hline$t_{\max }$ & hours & 43 & 2.4 \\
\hline $\mathrm{AUC}_{(0-60 h)}$ & $\mu \mathrm{g} \cdot \mathrm{h} / \mathrm{mL}$ & 67.48 & 2.2 \\
\hline $\mathrm{CL}=\left(\mathrm{D} / \mathrm{AUC} \mathrm{C}_{\mathrm{tot}}\right)$ & $L / h$ & 6.96 & 8.6 \\
\hline
\end{tabular}


Table II - Ropivacaine population pharmacokinetic results

\begin{tabular}{|l|c|c|c|}
\hline Parameter & Unit & Mean & $\begin{array}{c}\text { Percent Coefficient of } \\
\text { Variation }\end{array}$ \\
\hline $\begin{array}{l}\text { Apparent Clearance } \\
(\mathrm{CL} / \mathrm{F})\end{array}$ & $\mathrm{L} / \mathrm{h}$ & 5.33 & 21.69 \\
\hline $\begin{array}{l}\text { Apparent Volume of } \\
\text { Distribution (Vd/F) }\end{array}$ & $\mathrm{L}$ & 92.15 & 16.42 \\
\hline
\end{tabular}

Values are mean (percent coefficient of variation) 


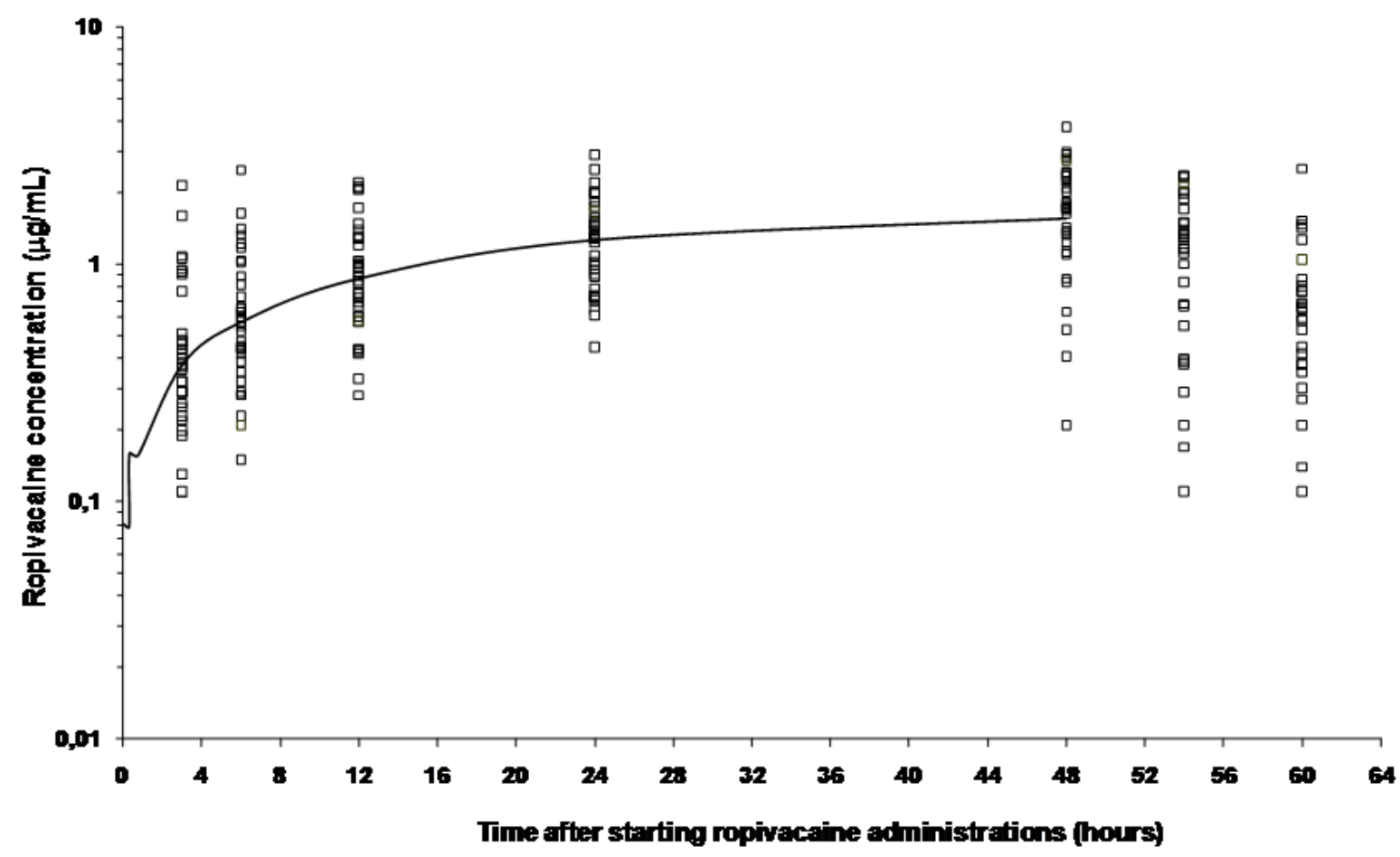

Figure 1. Total plasma ropivacaine concentration versus time during and after an epidural continous infusion of $10 \mathrm{mg} / \mathrm{hour}$ preceeded by 2 sequential epidural boluses. The solid line shows the computer-generated line of the best fit up to $48 \mathrm{~h}$, for a one-compartment model with zero-order input and first-order elimination. 


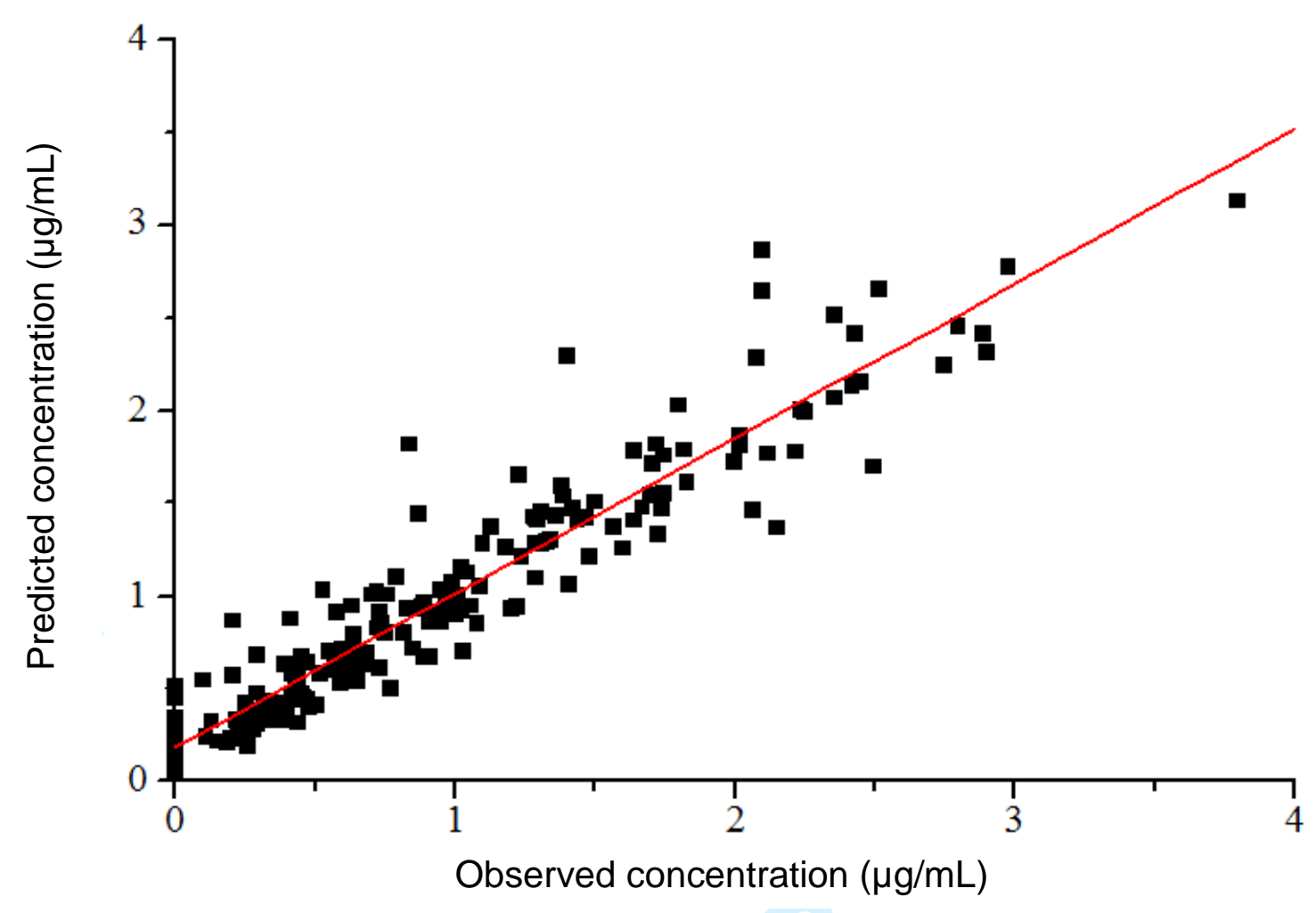

Figure 2. Scatterplot of estimated versus measured serum concentrations, in micrograms per milliliter, based on individual patient Bayesian posteriori parameter distributions. Pooled data of all 43 patients. 


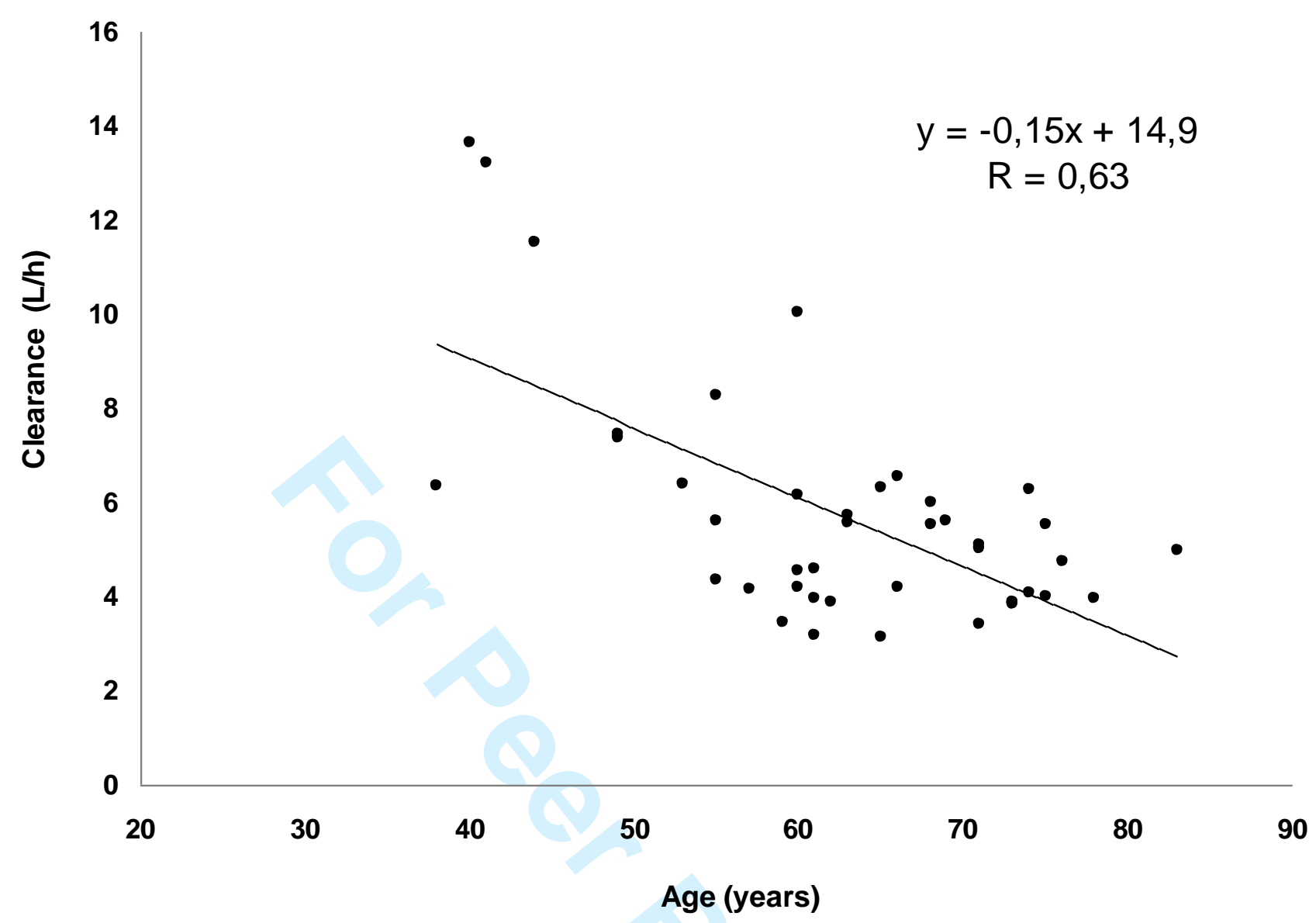

Fig 3. Relationship between ropivacaine total clearance (L/h) and age (years) 